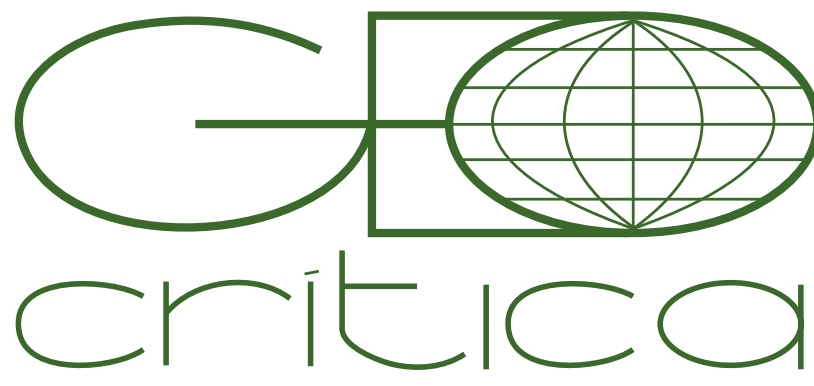

\section{Scripta Nova}

Revista Electrónica de Geografía y Ciencias Sociales Universitat de Barcelona

1 de febrero de 2017

\title{
LA INVERSIÓN DIRECTA DE ESPAÑA EN MÉXICO EN LA ERA DEL NEOLIBERALISMO ECONÓMICO. DINÁMICA TEMPORAL, ESTRUCTURA SECTORIAL Y DISTRIBUCIÓN GEOGRÁFICA
}

\author{
María Teresa Sánchez Salazar \\ Departamento de Geografía Económica. Instituto de Geografía. \\ Universidad Nacional Autónoma de México (UNAM), México. \\ mtss@igg.unam.mx \\ José Luis Alonso Santos \\ Departamento de Geografía. Universidad de Salamanca, España. \\ jlalonso@usal.es \\ José María Casado Izquierdo \\ Departamento de Geografía Económica. Instituto de Geografía. \\ Universidad Nacional Autónoma de México (UNAM), México. \\ chema@igg.unam.mx
}

Recibido: 9 de febrero de 2015. Aceptado: 16 de julio de 2016.

Este trabajo se deriva del proyecto titulado "Globalización, políticas neoliberales y transformaciones en la organización espacial de la economía en México" (clave PAPIIT IN301612) el cual fue financiado por la Dirección General de Asuntos del Personal Académico de la Universidad Nacional Autónoma de México (DGAPA-UNAM), a través del Programa de Apoyo a Proyectos de Investigación e Innovación Tecnológica (PAPIIT).
Resumen. La inversión directa de España en México en la era del neoliberalismo económico. Dinámica temporal, estructura sectorial y distribución geográfica A partir de los cambios estructurales implementados en la economía mexicana durante los decenios 1980-1990, México se convirtió en destino preferencial de la inversión española en Latinoamérica pero su comportamiento mostró diferencias notorias durante el periodo 1993-2013. La investigación examina con detalle, primeramente, la evolución de la inversión directa de España en México desagregada por ramas económicas de destino en tres fases que marcan momentos clave en la evolución reciente de la economía española y la relaciona con las reformas estructurales realizadas en la economía mexicana. En la segunda parte, la investigación profundiza en la distribución geográfica de dichas inversiones en las entidades federativas de México, identificando procesos de concentración espacial y diferenciando la intensidad y las ramas económicas de inversión según su destino geográfico. Se resalta el papel protagónico del capital y las empresas españolas en México en ramas específicas y la tendencia a su expansión futura.

Palabras clave: inversión directa de España, México, neoliberalismo económico, distribución geográfica, estructura sectorial de la economía 


\section{Abstract. Spanish direct investment in Mexico in Neoliberal times. Temporal dynamics, sectoral structure and geographical distribution}

From the structural changes in the Mexican economy implemented during 1980-1990, Mexico became the preferential target for Spanish investment in Latin America; however, its behavior revealed marked differences during 1993-2013. This investigation conducts an in-depth review, firstly, of the evolution of Spain's direct investment in Mexico, segregated by economic target sector in three stages which mark key moments in the recent evolution of the Spanish economy, and associates them with the structural reforms in the Mexican economy. Secondly, the investigation analyzes the geographic distribution of such investments in Mexico's States, identifying spatial concentration processes and differentiating the intensity of investment and its economic sectors according to the geographical targets. The leading role of Spanish capital and businesses in Mexico in specific sectors is highlighted, as well as the trend towards a future expansion.

Keywords: Spain's direct investment, Mexico, economic neoliberalism, geographical distribution, sectorial structure of the economy

A partir del decenio de 1990, hubo un aumento creciente de la inversión directa de España en América Latina, y México se convirtió en uno de los principales países de destino de dicha inversión desde entonces. Este aumento en la atracción de importantes empresas españolas para invertir en el país coincidió con la implementación de políticas liberalizadoras de la economía aplicadas por el gobierno federal que modificaron la legislación vigente hasta entonces y favorecieron la privatización de algunos sectores y ramas estratégicas de la economía originalmente bajo control estatal y la apertura hacia la IED. Los montos de las inversiones españolas y los sectores y ramas de destino han ido cambiando en el lapso de 1993-2013, así como la distribución geográfica preferencial de dichas inversiones. El presente trabajo tiene como objetivos analizar la evolución de la inversión directa de España en México, en el marco de la dinámica temporal experimentada por dicha inversión en el contexto latinoamericano durante el periodo 1993-2013, identificando los principales sectores y ramas económicas de destino y las variaciones en su comportamiento en el lapso señalado y desde la perspectiva geográfica; asimismo, se busca examinar las principales razones que explican la expansión, la estructura sectorial y la distribución territorial de la inversión directa de origen español en México, así como los beneficios que ha representado tanto para las empresas españolas como para la economía y las regiones de México.

Para el desarrollo de este trabajo, se tomó como base la información estadística derivada de diversas fuentes oficiales tanto de España como de México. Primeramente se analizaron los datos estadísticos sobre inversión española en el exterior, que facilita la Secretaría de Estado de Comercio de España a través de DataInvex para el periodo enero 1993 a diciembre 2013, para un desglose de 88 ramas de producción, los cuales se consultaron en junio de 2014. Para el análisis de la IED española en México por sectores económicos y entidades federativas, se utilizaron las bases de datos que publica anualmente la Secretaría de Economía de Méxicoํ. Asi-

1 Secretaría de Economía, 2014a. 
mismo, se consultaron los directorios de empresas españolas establecidas en México publicadas por ICEX España Exportación e Inversiones en $2012^{2}$ y $2014^{3}$, y los directorios de empresas "Industridata", publicados en cuatro volúmenes, de acuerdo con el número de trabajadores, por la empresa Mercamétrica ${ }^{4}$ en México. Con esta información se elaboraron cuadros y material gráfico y cartográfico que facilitaron el análisis de la dinámica temporal de la inversión directa de España en Latinoamérica y en México, así como su estructura sectorial y la distribución geográfica de dichas inversiones. Para la obtención de información cuantitativa sobre la importancia que para las empresas españolas tiene el mercado mexicano, en términos de los beneficios obtenidos en el año 2013, se consultaron los informes anuales de las principales empresas de cada sector económico con presencia en México. Sin embargo, no fue posible obtener la información señalada en todos los casos, debido a la ausencia de datos concretos sobre México en los informes señalados, bien por ofrecer cifras desglosadas por áreas geográficas más amplias (América o América Latina), bien por no ofrecer datos de beneficios con algún desglose geográfico. Así, para ciertas empresas fue necesario aludir a otros conceptos (número de tiendas, energía eléctrica generada, etc.) a fin de ponderar la importancia que para estas empresas tiene su presencia en el país.

En relación con las fuentes oficiales españolas consultadas, la fuente de información DataInvex es una potente herramienta que facilita las estadísticas de la inversión española en el exterior atendiendo a flujos de inversión y stock de negocio de las empresas que salen al exterior. Facilita el país de destino y el sector económico al que accede la empresa así como al que pertenece en España o la comunidad autónoma de domicilio. El potencial de desglose de los datos a nivel de dos o cuatro dígitos de la clasificación de actividades económicas de la CNAE-2009 hace de esta fuente el instrumento más completo de información para el estudio de la internacionalización de las empresas españolas.

Con respecto a las fuentes oficiales mexicanas, cabe hacer la aclaración de que existe un sesgo en relación con las entidades federativas en donde aparece registrada la IED que hay que tomar en cuenta: las empresas inversoras están obligadas a declarar el monto de su inversión en el país pero no el lugar específico donde dicha inversión se va a realizar, por lo en ocasiones ésta aparece registrada en el Distrito Federal por ser el lugar donde se asientan las oficinas centrales de las empresas, cuando en realidad la inversión es ejercida en otras entidades federativas del país. Otro aspecto a considerar en la valoración del monto de las inversiones a nivel regional, son las fluctuaciones en las tasas de cambio de las monedas extranjeras frente al peso mexicano, en virtud de que un mismo monto de inversión (en dólares estadounidenses, euros u otra moneda) supone un impacto local mayor o menor en función de dicha fluctuación.

2 ICEX, 2012.

3 ICEX, 2014.

4 Mercamétrica, 2014. 


\section{Antecedentes}

La capacidad de la economía española como actor importante de la inversión extranjera directa sólo adquirió relevancia avanzados los años 80 de la centuria pasada, siendo América Latina región de temprana y sólida implantación. La desregulación de movimientos de capitales a escala planetaria que supuso la era de la globalización, no sólo potenció la inversión exterior directa (IED), sino que su naturaleza, volumen y dirección geográfica pasaron a ser objeto de estudio y análisis constante. $\mathrm{Al}$ respecto, la inversión extranjera directa de España en México, en cuanto a su evolución, características y expansión geográfica, ha sido poco analizada por los científicos sociales, y menos aún por los geógrafos, pese a la dinámica que experimentó y a la relevancia que fue alcanzando sobre todo a partir del decenio de 1990.

Los trabajos que analizan el comportamiento de la IED en América Latina se suceden con regularidad en las últimas décadas; en este sentido cabe resaltar los informes anuales que la Comisión Económica para América Latina y el Caribe (CEPAL) de Naciones Unidas publica bajo el título "La inversión extranjera en América Latina y el Caribe" (1997-2007)5 y "La inversión extranjera directa en América Latina y el Caribe" (2008-2013) ${ }^{6}$ en los cuales se analiza el comportamiento de dichas inversiones, sus patrones de origen y destino por países y se profundiza en la presencia de la IED en los sectores preponderantes de la economía de algunos países. En particular, el informe de $1999^{7}$ dedica un capítulo a la IED en México, a su comportamiento a lo largo del decenio de los 90 y a las estrategias seguidas por las empresas trasnacionales en dicho país, y consagra otro capítulo a España y a sus inversiones y estrategias empresariales en América Latina. Por su parte, el Instituto de Empresa (IE) Bussiness School de España ${ }^{8}$ ha publicado también algunos informes en donde brinda un panorama acerca de la evolución reciente de las inversiones españolas en la región latinoamericana como destino preferente, las oportunidades de inversión y las nuevas tendencias en las relaciones comerciales de este país. Sobre el proceso de internacionalización de las empresas españolas en América Latina, los factores determinantes de la elección de esta región como destino de las inversiones, su proceso de penetración y las empresas con mayor presencia en los distintos sectores de la economía, la literatura científica acumula trabajos más tempranos como los de Pampillón y Fernández ${ }^{9}$, Muñoz ${ }^{10}$, o Casilda ${ }^{11}$ junto a los recientes de Arahuetes ${ }^{12}$, Doval ${ }^{13}$ o Alberola y López ${ }^{14}$; a su vez, el trabajo de Morales ${ }^{15}$ trata sobre las implica-

5 CEPAL, 1998-2008.

6 CEPAL, 2009-2014.

7 CEPAL, 2000.

8 IE Bussiness School, 2013 y 2014.

9 Pampillón y Fernández, 1999.

10 Muñoz, 2001.

11 Casilda, 2002 y 2005.

12 Arahuetes, 2011.

13 Doval, 2013.

14 Alberola y López, 2013.

15 Morales, 2010. 
ciones de estas inversiones en el desarrollo de la región.

Por su parte, el análisis de la inversión extranjera en México desde una perspectiva general, ha sido abordado por diferentes autores. La evolución de la inversión extranjera en México a lo largo del siglo pasado, en particular durante el periodo de industrialización del país y en el decenio de la crisis económica de los 80, así como su impacto en la economía y concretamente en la industria manufacturera, ha sido tratado por autores como Aguilar, et al. ${ }^{16}$, Ornelas ${ }^{17}$ y López ${ }^{18}$. Entre los trabajos más recientes que analizan el comportamiento de la IED y sus implicaciones desde un enfoque económico, son dignos de mención los de Rodríguez ${ }^{19}$ y Mendoza ${ }^{20}$. Finalmente, Dussel ${ }^{21}$ ha publicado tres obras donde, además de examinar la evolución de la IED en el marco de los más recientes cambios legislativos y el modelo económico neoliberal, profundiza en las estrategias empresariales, en su desempeño y en la complejidad de sus efectos considerando distintas escalas geográficas de aproximación, además de abordar el papel de la IED en la especialización geográfica de los territorios y cuestionar su debilidad para generar procesos de innovación.

En particular, el tema de la inversión española en México ha ocupado un lugar preferente en los informes y estudios sobre la inversión de España en América Latina, además de acumular estudios e informes específicos en consonancia con la potente atracción ejercida por la economía mexicana para el capital español en las dos últimas décadas. Junto a los documentos elaborados por España Exportación e Inversiones (ICEX), organismo adscrito al Ministerio de Economía y Competitividad, el tema ha sido reflexionado en dos trabajos elaborados en la Universidad Antonio de Nebrija. El primero deriva de la tesis doctoral de Delgadillo de Lira ${ }^{22}$, que versa sobre el análisis de los factores determinantes de la internacionalización de la empresa española en México; el segundo, coordinado por Solana ${ }^{23}$, reseña las experiencias de un conjunto de empresas españolas en México y sus oportunidades, en el contexto del entorno económico del país. A su vez, El Real Instituto Elcano (en colaboración con el Instituto de Crédito Oficial -ICO-) ha presentado un amplio estudio sobre las oportunidades de la economía de México para las empresas españolas dirigido por Arahuetes y Elozondo. ${ }^{24}$ Desde la misma perspectiva empresarial, Price waterhouse Coopers (PwC) México ${ }^{25}$ ha publicado los resultados de una encuesta aplicada a los directores generales de las principales empresas españolas establecidas en México en la cual se hace referencia a temas como el contexto económico global y de México, el enfoque estratégico de las empresas, sus estrategias de reestructuración

16 Aguilar, et al., 1986.

17 Ornelas, 1991.

18 López, 1993.

19 Rodríguez, 2009.

20 Mendoza, 2011.

21 Dussel, 2000, 2007 y 2012.

22 Delgadillo de Lira, 2005.

23 Solana, 2012.

24 Arahuetes y Elozondo, 2008.

25 PwC-COMCE, 2011. 
organizacional y ubicación territorial, el papel de la innovación y las ventajas y desventajas de las políticas laborales en el país. Finalmente, en la literatura científica reciente sobre las relaciones económicas España/México han sido varios los autores que las han abordado -Zaballa ${ }^{26}$, Moreno y Pérez ${ }^{27}$, Rodríguez ${ }^{28}$, Pérez ${ }^{29}{ }^{-}$, los cuales se centran en el análisis de la IED de las empresas españolas o más específicamente en el sector de la energía ${ }^{30}$.

\section{Presentación. La inversión exterior de España}

La internacionalización de la economía española es relativamente reciente y se ha manifestado con intensidad, siendo América Latina, fuera de la Unión Europea (UE), la región primera y de más elevado posicionamiento de la inversión extranjera directa procedente de este país. Si bien la IED es uno de los sólidos indicadores de la mayor o menor intensidad de la internacionalización de una economía en la era de la globalización, ello daría lugar en las postrimerías de la centuria pasada a la percepción, desde ciertos círculos de opinión en América Latina, de que España volvía a la conquista, en esta ocasión económica, y pondría de manifiesto la pervivencia de cierto recelo hacia el capitalismo tanto español como global.

La inmersión exterior de las empresas españolas en los años 90 del siglo pasado se intensificó notablemente respecto a la fase anterior -iniciada con el ingreso en la UE- llegando al 10 por ciento del PIB nacional en $2000^{31}$ y prosiguió su incremento en los años siguientes hasta alcanzar en 2007 su máximo histórico anual, con cerca de cien mil millones de euros, cifra superior al 10\% del PIB español de la fecha ${ }^{32}$. El flujo de IED redujo drásticamente su volumen en el bienio inicial de la severa crisis económica que aún padece el país, recuperó intensidad en el siguiente para, de nuevo, contraer su volumen en 2012 y 2013, en una cadencia en el tiempo muy acorde a la que experimentó la IED mundial aunque con deterioro más intenso en el último bienio. ${ }^{33}$

Con el fin analizar los ritmos de inversión española en las distintas ramas de actividad se ha optado por establecer tres subperíodos acordes con el comportamiento de la misma y los eventos económicos que propiciaron los cambios en dicho comportamiento. Los periodos identificados fueron los de 1993-2000, 2001-2007 y 2008-2013. En efecto, la IED de España, que ascendió a 582.464,4 millones de euros de 1993 a $2013^{34}$, presentó incrementos anuales medios sin cesar hasta el inicio de la

26 Zaballa, 2000.

27 Moreno y Pérez, 2005.

28 Rodríguez, 2009.

29 Pérez, 2009.

30 Sánchez-Salazar, Alonso y Casado, 2007.

31 Gutiérrez y García de Quevedo, 2012, p. 222.

32 Alberola y López, 2013, p. 61.

33 UNCTAD, 2012 y 2013.

34 Secretaría de Estado de Comercio de España. Datainvex. Estadísticas de inversión española en el exterior [en línea] [http://datainvex.comercio.es/principal_invex.aspx] Consulta final: 23 de junio de 2014. 
crisis económica actual. En el periodo 1993-2000 la IED anual media fue de 16.582,7 millones de euros; de 2001 a 2007 se elevó de forma notoria hasta alcanzar 42.887,1 millones de euros para, finalmente, contraerse en los años de crisis económica 20082013, a 24.932,2 millones de euros anuales.

El análisis de la serie estadística que ofrece DataInvex desde el año 1993, revela que durante el periodo 1993-2013, América Latina recibió unos 155.772,7 millones de euros de IED de España, equivalentes al 26,74 por ciento de toda la inversión exterior del país acumulada para el periodo y hace de América Latina la segunda región geográfica receptora de la IED española después de la Unión Europea (UE-27) que desde 1986, con el ingreso de España, se convirtió en la receptora dominante (54,8\% del total) de los flujos de inversión exterior de este país. Si a estos dos espacios se añade América del Norte, los tres aglutinaron más del 91 por ciento de la IED de España en el periodo 1993-2013 conformando una orientación geográfica muy definida que sólo en los recientes años de crisis económica se abrió ligeramente a los mercados de Asia y África ${ }^{35}$. Cabe destacar que América Latina enlazó todo un quinquenio (1996-2000) como receptor principal de la IED española (73.003,7 millones frente a 28.649,6 millones recibidos por UE-27), culminando así el periodo calificado por Casilda como "la década dorada" ${ }^{36}$ (figura 1). Este periodo coincide precisamente con la aplicación de políticas económicas neoliberales en los países de la región latinoamericana a consecuencia de la crisis económica de los años ochenta y del crecimiento sin precedente de la deuda externa que dieron como resultado la liberalización del comercio internacional, la privatización de empresas públicas que habían conformado monopolios en sectores estratégicos de la economía y la apertura hacia la inversión extranjera. ${ }^{37}$ Este proceso fue similar al ocurrido en España con la liberalización de varios sectores económicos (telecomunicaciones, electricidad, gas natural y petróleo), lo que vigorizó la competencia al interior del país con la llegada de empresas de la Unión Europea y reforzó la necesidad de las grandes empresas españolas de desarrollar estrategias para expandir sus actividades a nivel internacional, de modo que la coyuntura de los programas económicos liberalizadores en los países latinoamericanos, -a los que se suma la afinidad cultural y lingüística derivada de los lazos históricos-, incentivaron a las firmas españolas internacionalizadas a aprovechar las oportunidades de negocio que se abrían en los sectores económicos en proceso de privatización en estos países para realizar fuertes inversiones ${ }^{38}$.

Por el contrario, en los años transcurridos de la centuria actual la inversión directa de España en la región perdió intensidad cada año (figura 1) hasta quedar reducida apenas al 5,5 por ciento en 2006, como reflejo de que las principales reformas y los procesos de apertura económica de los sectores más importantes habían culminado en la mayoría de los países. No obstante, en los años de la crisis económica dicha inversión remontó a niveles del 18 al 27 por ciento elevándose incluso en

35 Durán, 2014. p. 194.

36 Casilda, 2002, p. 3 y 2005, p. 11.

37 Muñoz, 2001, p. 838.

38 Ibid., p. 836-837; Arahuetes, 2011, p. 81. 
2012 al 39,1 por ciento del total de la IED de España, con lo cual este país mantuvo el liderazgo inversor en Latinoamérica entre los 28 socios de la Unión Europea. ${ }^{39}$ Ello se explica porque durante esta etapa, las grandes empresas ya instaladas en la región continuaron su expansión y diversificaron sus actividades y áreas de negocio para aprovechar el mercado potencial y sus perspectivas de crecimiento como una estrategia para contrarrestar la crisis en España, además de que su presencia suscitó un fenómeno de atracción sobre empresas medianas y pequeñas proveedoras de bienes y servicios, que se concretó en una nueva oleada de inversiones, si bien de menor magnitud a las del decenio anterior.

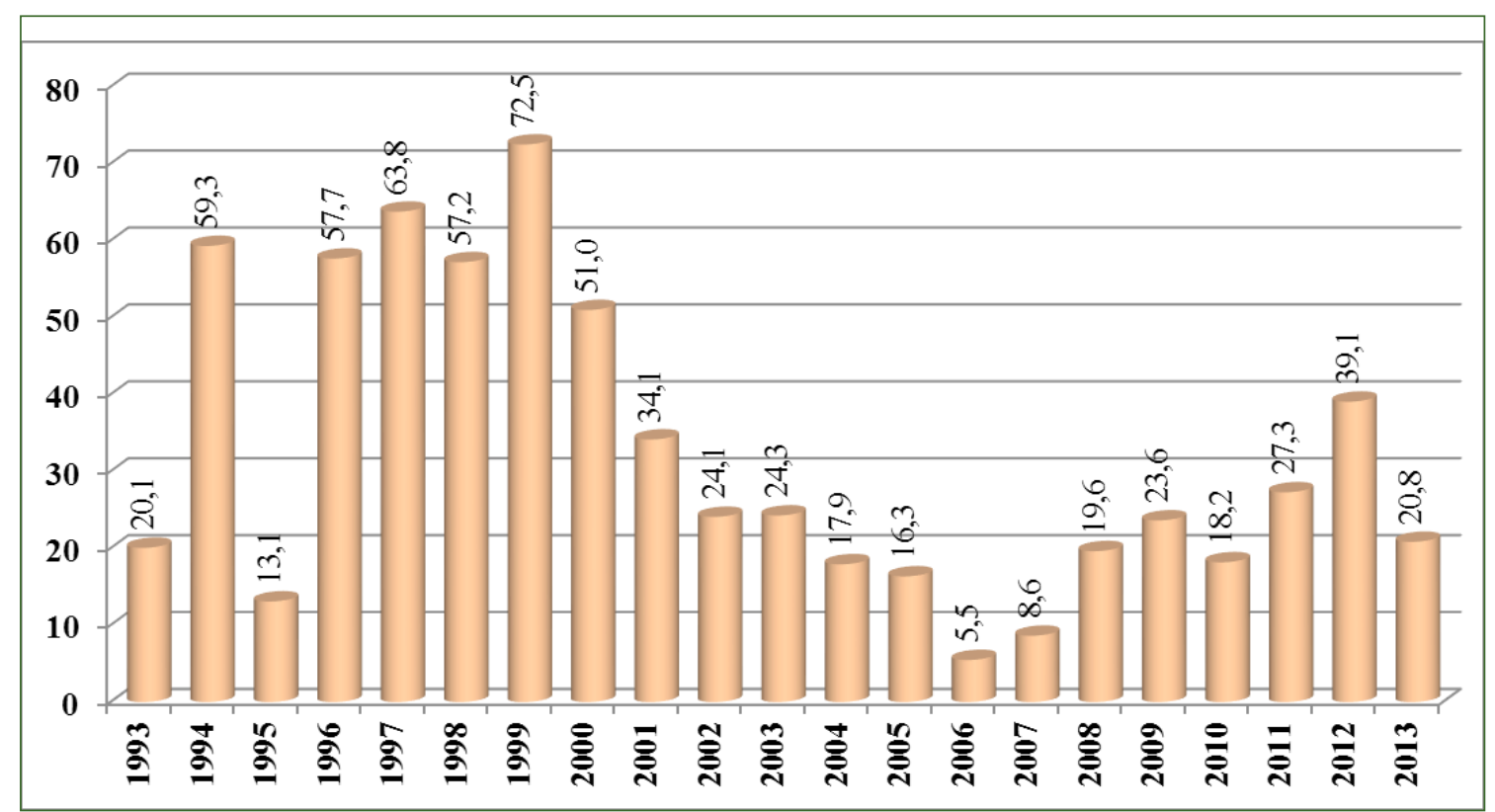

Figura 1. Participación de América Latina en la IED total de España en el periodo 1993-2013 (\%) Fuente: Secretaría de Estado de Comercio. Datalnvex. Junio de 2014.

\section{La inversión española en América Latina}

El retorno de la confianza en la economía de los países de América Latina por parte del capital internacional desde los años 90 del siglo XX, fue vigoroso y sostenido a la vista del aumento del volumen de la inversión recibida y de la participación relativa de la región en el total de la IED mundial. Se pasó de un promedio anual de 40.080 millones de dólares en 1994-1998, a 68.939 millones en 1999-2003 y a 91.207 millones promedio de 2004 a 2008, año en el que alcanzaron los 128.301 millones de dólares ${ }^{40}$, escalando en los años siguientes, tras la contracción de 2009, a un techo de 188.000 millones de dólares en 2013, equivalentes al 13 por ciento de la IED mundial, muy por encima del 7,7 por ciento alcanzado en $2008^{41}$. Quedaron lejos las débiles entradas de IED de principios del decenio de 1990 (promedio anual de solo

39 CEPAL, 2012.

40 CEPAL, 2009.

41 CEPAL, 2013. 
17.429 millones de dólares para el bienio 1992-199342, cuando resonaban aún las secuelas negativas de la denominada "década perdida" en la región y sus repercusiones en el entorno internacional.

Los profundos cambios estructurales operados en la economía de los países de la región latinoamericana conducentes a una mayor apertura hacia el comercio y las inversiones externas en el marco de los acuerdos internacionales para la circulación de capitales, incrementaron la confianza e incentivaron el interés del capital internacional y del español en particular por invertir en sectores económicos de oportunidad. Existe amplio consenso entre los analistas ${ }^{43}$ en resaltar que las importantes medidas implementadas en América Latina en el decenio de 1990 a favor de la liberalización económica y el incremento de la seguridad jurídica de la inversión exterior, a la vez que las múltiples privatizaciones de empresas públicas, principalmente industriales y de servicios, fueron el principal incentivo para la IED.

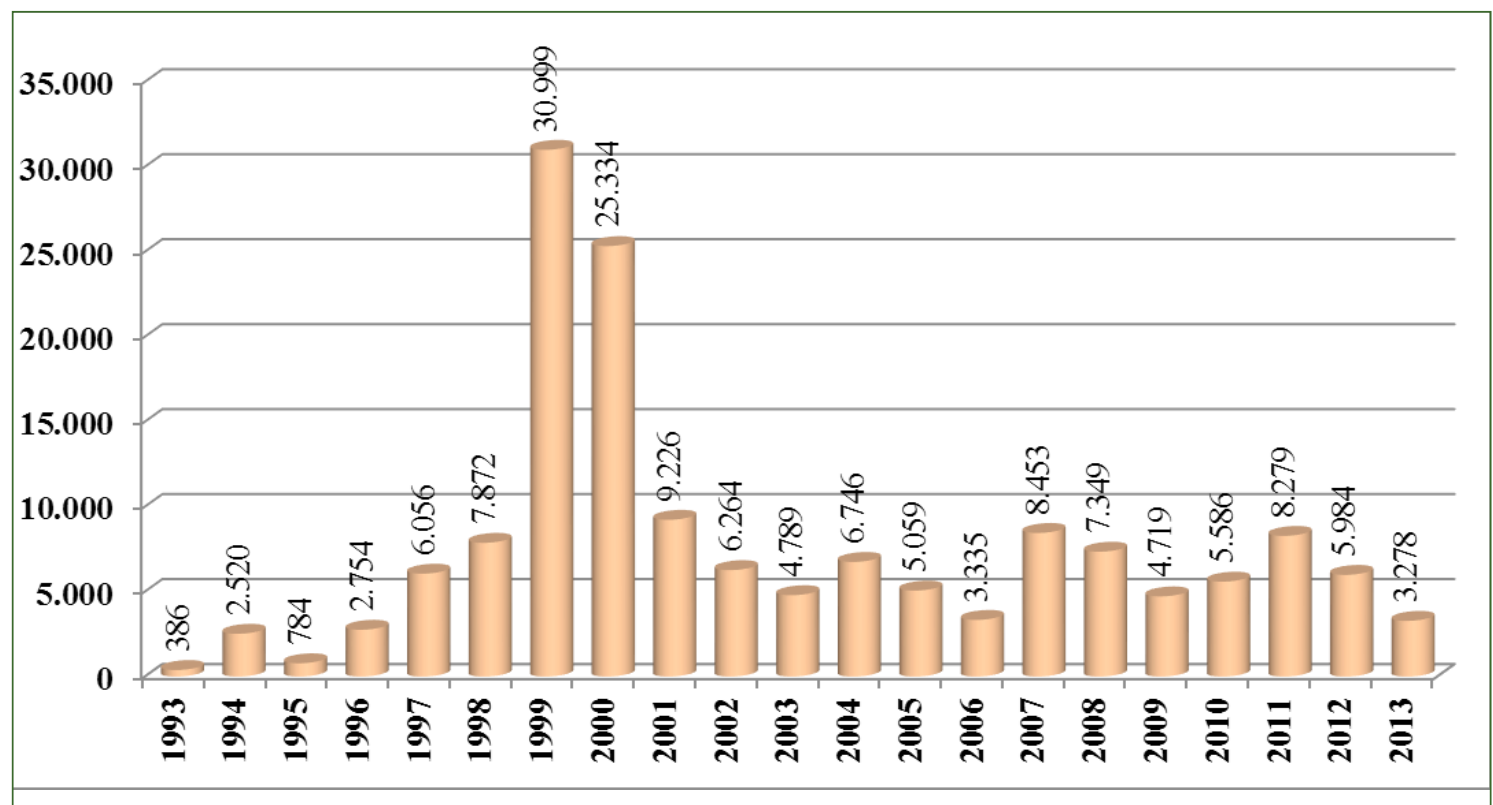

Figura 2. Inversión directa de España en América Latina, 1993-2013 (Millones de euros). Fuente: Secretaría de Estado de Comercio. Datalnvex.

Los 26,74 euros que llegaron a Latinoamérica de cada 100 invertidos en el exterior por las empresas españolas entre 1993 y 2013, presentaron en el tiempo y el espacio un comportamiento muy desigual. La figura 2 ilustra los contrastes de los flujos de inversión de unos años a otros.

En la cronología temporal destacó el trienio 1993-1995 por sus débiles inversiones en contraste con las cifras espectaculares que concentró el bienio 1999-2000. En esos años del decenio de los noventa, señala CEPAL en su informe anual sobre

42 UNCTAD, 1998.

43 Pampillón y Fernández, 1999, p. 58; Zaballa, 2000, p. 59; Casilda, 2005, p. 14; Delgadillo de Lira, 2005, p. 12; Moreno y Pérez, 2005, p. 234. 
la Inversión Extranjera Directa ${ }^{44}$, la inversión española fue protagonizada por pocas empresas de gran tamaño y muy polarizada en servicios estratégicos con gran potencial de crecimiento, como el financiero (bancos Santander y BBVA), las telecomunicaciones (Telefónica) y el transporte (Iberia), así como el subsector de la energía -petróleo, electricidad, gas natural- y el agua (Repsol, Unión Fenosa, Iberdrola, Gas Natural y Endesa).

El volumen de inversión fue decreciente45 de 2001 a 2006 con excepción de 2004, y ante la perspectiva de agotamiento del ciclo expansivo de la economía española, el capital volvió a mirar a la región con mayor interés en los años 20072008, mientras la inversión se hundió en los peores años de la crisis, situación que tras el repunte de 2011, se prolongó agravada hasta el presente, pues el año 2013, contraviniendo las previsiones optimistas ${ }^{46}$, arrojó un saldo tan bajo que hay que retrotraerse hasta 1996 para encontrar cifras inferiores. Las desinversiones de algunas empresas acuciadas por la intensidad de la crisis en España, ${ }^{47}$ más el desaliento que provocó la falta de certeza jurídica para los capitales extranjeros en algunos países de la región, coadyuvaron a la atonía de la inversión. En suma, la tradicional preferencia inversora de las empresas españolas por América Latina en la centuria actual se debilitó, ${ }^{48}$ y en contraste mantuvo su orientación hacia los países de la UE, incrementó su presencia en América del Norte y en los últimos años experimentó una apertura a los mercados de Asia y África si bien en grado aún reducido.

También por país de destino de la IED española en la región, las diferencias fueron muy notorias y previsibles dada la gran diferencia de tamaño de mercado entre los países, aunque factores como la incertidumbre normativa en algunos de ellos influyeron en la orientación del flujo inversor. Así, durante el periodo 1993-2013 tres países (Argentina, Brasil y México) absorbieron el 75 por ciento de la inversión procedente de España y superaron el 90 por ciento cuando se agrega a otros países como Chile y Perú.

\section{México: destino principal de la inversión directa de España en América Latina}

El cuadro 1 expresa la evolución y los cambios en el tiempo del ritmo de inversión en cada uno de los países de la región y permite establecer en distintos periodos qué países fueron los que mayor capacidad de atracción ofrecieron al capital español.

\footnotetext{
44 CEPAL, 2000a.

45 Pérez, 2009, p. 102.

46 El informe titulado Panorama de la Inversión Española en Latinoamérica 2014. VII Informe preveía en sus conclusiones, tras pulsar la opinión de las empresas consultadas, el repunte de la inversión en la región. Martínez Lázaro, 2014, p. 3-4.

47 Alberola y López, 2013, p. 63.

48 El porcentaje recibido por la región entre 2001 y 2008 cae al 21 por ciento del total según Alberola y López, 2014, p. 63.
} 


\begin{tabular}{|l|r|r|r|r|r|r|r|r}
\hline \multirow{2}{*}{ País } & \multicolumn{2}{|c|}{$\mathbf{1 9 9 3}-\mathbf{2 0 0 0}$} & \multicolumn{2}{|c|}{$\mathbf{2 0 0 1 - 2 0 0 7}$} & \multicolumn{2}{c|}{$\mathbf{2 0 0 8 - 2 0 1 3}$} & \multicolumn{2}{c}{$\mathbf{1 9 9 3 - 2 0 1 3}$} \\
\cline { 2 - 8 } & Inversión & \% A. Latina & Inversión & \% A. Latina & Inversión & \% A. Latina & Inversión & \% A. Latina \\
\hline Brasil & 28.139 & 36,7 & 11.087 & 24,4 & 10.696 & 30,4 & 49.922 & 31,7 \\
\hline Argentina & 24.879 & 32,4 & 6.820 & 15,0 & 1.815 & 5,2 & 33.514 & 21,3 \\
México & 6.220 & 8,1 & 14.114 & 31,0 & 12.311 & 35,0 & 32.644 & 20,7 \\
Chile & 6.742 & 8,8 & 4.447 & 9,8 & 3.503 & 10,0 & 14.691 & 9,3 \\
Perú & 3.119 & 4,1 & 2.960 & 6,5 & 1.320 & 3,7 & 7.398 & 4,7 \\
Colombia & 2.878 & 3,8 & 980 & 2,2 & 1.879 & 5,3 & 5.737 & 3,6 \\
\hline Venezuela & 1.045 & 1,4 & 1.598 & 3,5 & 337 & 1,0 & 2.980 & 1,9 \\
\hline Uruguay & 469 & 0,6 & 1.107 & 2,4 & 937 & 2,7 & 2.512 & 1,6 \\
Panamá & 1.047 & 1,4 & 459 & 1,0 & 531 & 1,5 & 2.036 & 1,3 \\
R. Dominicana & 203 & 0,3 & 967 & 2,1 & 257 & 0,7 & 1.426 & 0,9 \\
\hline Cuba & 834 & 1,1 & 30 & 0,1 & 59 & 0,2 & 923 & 0,6 \\
Guatemala & 408 & 0,5 & 267 & 0,6 & 237 & 0,7 & 912 & 0,6 \\
Ecuador & 175 & 0,2 & 207 & 0,5 & 369 & 1,0 & 751 & 0,5 \\
El Salvador & 142 & 0,2 & 124 & 0,3 & 377 & 1,1 & 643 & 0,4 \\
\hline Costa Rica & 18 & 0,0 & 151 & 0,3 & 396 & 1,1 & 565 & 0,4 \\
\hline Bolivia & 125 & 0,2 & 112 & 0,2 & 2 & 0,0 & 239 & 0,2 \\
\hline Nicaragua & 146 & 0,2 & 12 & 0,0 & 22 & 0,1 & 180 & 0,1 \\
\hline Honduras & 58 & 0,1 & 15 & 0,0 & 40 & 0,1 & 113 & 0,1 \\
\hline Paraguay & 22 & 0,0 & 8 & 0,0 & 74 & 0,2 & 104 & 0,1 \\
\hline Guyana & 0 & 0,0 & 0 & 0,0 & 35 & 0,1 & 35 & 0,0 \\
Belice & 0 & 0,0 & 1 & 0,0 & 0 & 0,0 & 1 & 0,0 \\
\hline América Latina & $\mathbf{7 6 . 6 6 8}$ & $\mathbf{1 0 0 , 0}$ & $\mathbf{4 5 . 4 6 3}$ & $\mathbf{1 0 0 , 0}$ & $\mathbf{3 5 . 1 9 6}$ & $\mathbf{1 0 0 , 0}$ & $\mathbf{1 5 7 . 3 2 7}$ & $\mathbf{1 0 0 , 0}$ \\
\hline
\end{tabular}

Cuadro 1. Ciclos de la inversión española en los países de América Latina (Millones de euros). Fuente: Secretaría de Estado de Comercio. Datalnvex. Junio de 2014.

Como se observa en dicho cuadro, México pasó de ser uno de los socios más relevantes de los años 90 del siglo pasado a ser el principal receptor de la IED española en América Latina en los años transcurridos de la actual centuria.

Durante el periodo 1993-2000, Brasil y Argentina se convirtieron, en ese orden, en los principales destinatarios de los flujos de inversión procedentes de España, como resultado de la adecuación temprana de sus marcos legislativos e institucionales para liberalizar sus economías e incentivar la atracción de capitales extranjeros, sobre todo en los sectores financiero, de la industria petrolera, electricidad, gas natural, agua y telecomunicaciones ${ }^{49}$. En conjunto, ambos países concentraron $69 \%$ de las inversiones españolas en la región, seguidos de forma más discreta por Chile, México y Perú, con 8,8, 8, 1 y 4,1 por ciento de las mismas, respectivamente; es decir, en este primer periodo México ocupó un modesto cuarto lugar como destinatario de las inversiones españolas en América Latina.

El protagonismo de México en América Latina y el Caribe se acrecentó notablemente en los años siguientes como resultado de las políticas económicas implementadas por el gobierno mexicano. En 1993 se decretó una nueva Ley de Inversión Extranjera (LIE) en la que se fijó una mayor apertura a la inversión en algunos sectores económicos antes reservados al propio gobierno mexicano e inversionistas

49 Arahuetes, 2011, p. 72. 
nacionales, ampliándose la proporción de participación permitida a capitales extranjeros. ${ }^{50}$ Sin embargo, fue hasta finales de ese decenio, con la aprobación del Reglamento de dicha ley ${ }^{51}$ cuando se intensificaron las inversiones de origen externo en los sectores económicos más atractivos como los servicios financieros, el transporte, las telecomunicaciones, la electricidad y el gas natural (incluyendo las energías renovables) así como los servicios de logística, recreativos y turísticos, de forma similar al resto de la región latinoamericana. Con estos cambios en la normatividad, la inversión extranjera en general y particularmente la procedente de España, recibió un impulso muy notorio como se observa en el cuadro l: la importancia adquirida por México como destinatario principal de la IED española, respecto a Brasil y Argentina, aumentó durante los periodos 2001-2007 y 2008-2013, desplazando a los países referidos a los lugares siguientes. En ambos lapsos, México alcanzó montos que representan 32,2 y 35,0 por ciento respectivamente de la IED procedente de España hacia la región. En conjunto, los tres países concentraron 72,7 por ciento de las inversiones españolas durante el periodo 2001-2007, y en tanto que México y Brasil mantuvieron su supremacía para el periodo más reciente (2008-2013), Argentina fue desplazada hasta el quinto puesto por Chile y Colombia.

En síntesis, mientras de 1993 a 2013 México absorbió el 21,0 por ciento de la IED de España en la región y se convirtió en el principal destino de la inversión española en América Latina ${ }^{52}$, sólo pasó a ser un socio destacado para el capital español en 2004 (figura 3), aunque gracias a los cambios establecidos en los años 90: asenta-

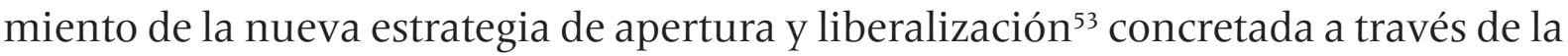
LIE de 1993 y su reglamento (1998), entrada en vigor del Tratado de Libre Comercio con EE.UU. y Canadá en enero de 1994, y superación de la crisis económica y de confianza desatada por el denominado "error de diciembre" de 1994, que desencadenó una fuerte depreciación del peso mexicano (efecto "Tequila"). Asimismo, México presentó la singularidad de que durante los años de la crisis económica española, en especial en el trienio inicial 2008-2010, (cuando acumuló 55,8\% del total de inversiones españolas en la región) su peso relativo en dichas inversiones se incrementó respecto de años anteriores, como lo refleja la figura 3.

50 D.O.F., 27 de diciembre de 1993.

51 Reglamento de la Ley de Inversión Extranjera y del Registro Nacional de Inversiones Extranjeras (RLIERNIE). D.O.F., 8 de septiembre de 1998.

52 Arahuetes y Elozondo, 2008, p. 169.

53 CEPAL, 2000b. 


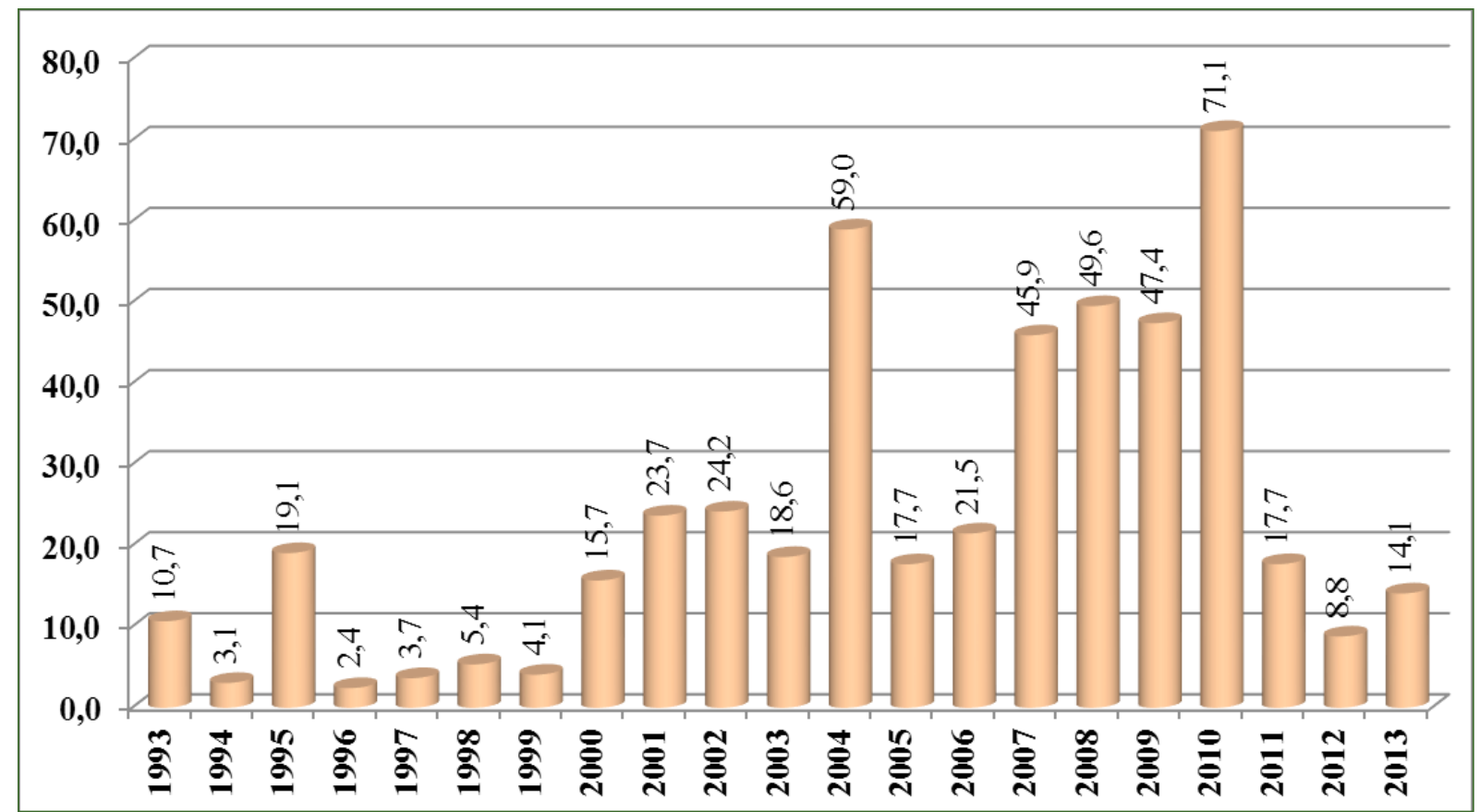

Figura 3.

Participación de México en la inversión directa de España en América Latina (\%). Fuente: Secretaría de Estado de Comercio. Datalnvex.

\section{Fases en la evolución de la IED española en México. Su naturaleza e intensidad}

La figura 4 muestra la evolución de la inversión directa de España en México desagregada por años. Los 32.644,5 millones de euros invertidos de 1993 a 2013 presentaron fuertes oscilaciones de un año a otro, lo que coincidió con la aplicación en México de algunas políticas dirigidas a la apertura de sectores o ramas de la actividad económica específicos que originalmente conformaban monopolios controlados por el Estado a la inversión extranjera, y que resultaron particularmente atractivos para las grandes empresas españolas internacionalizadas, tanto aquellas con sólida trayectoria en el país como las de implantación más reciente. Por su parte, la aguda crisis económica de España a partir de 2008, contrariamente a lo esperado, diversificó las actividades y áreas de negocio de las grandes firmas previamente establecidas en México e intensificó la afluencia de inversiones de empresas pequeñas y medianas a un mayor número de subsectores económicos.

En el periodo 1993-2000 el monto de la inversión española en México fue de $6.220,2$ millones de euros equivalentes al 19,05 por ciento de la inversión total (1993-2013), lo que se tradujo en una inversión media por año de 777,5 millones de euros, sin duda, la más baja de todo el tiempo analizado ciñéndose, al menos hasta 1995, a la industria de transformados metálicos, alimentación y bebidas, papel y artes gráficas junto a actividades comerciales en general. ${ }^{54}$ Sin embargo, ésta se in-

54 Arahuetes y Elozondo, 2008, p. 55-56. 
crementó en los años siguientes para ofrecer, en el último año del periodo, un volumen notorio de inversión $(3.978,1$ millones de euros, que representan 64 por ciento de la inversión total del periodo) que respondió fundamentalmente a la apertura del sector eléctrico iniciada en 1996 (construcción de centrales eléctricas de ciclo combinado y generación de electricidad) y la del sector financiero y bancario a la inversión extranjera ocurrida en $1999^{55}$, donde los capitales españoles aprovecharon importantes nichos de oportunidad, como un amplio mercado con perspectivas de crecimiento $^{56}$.

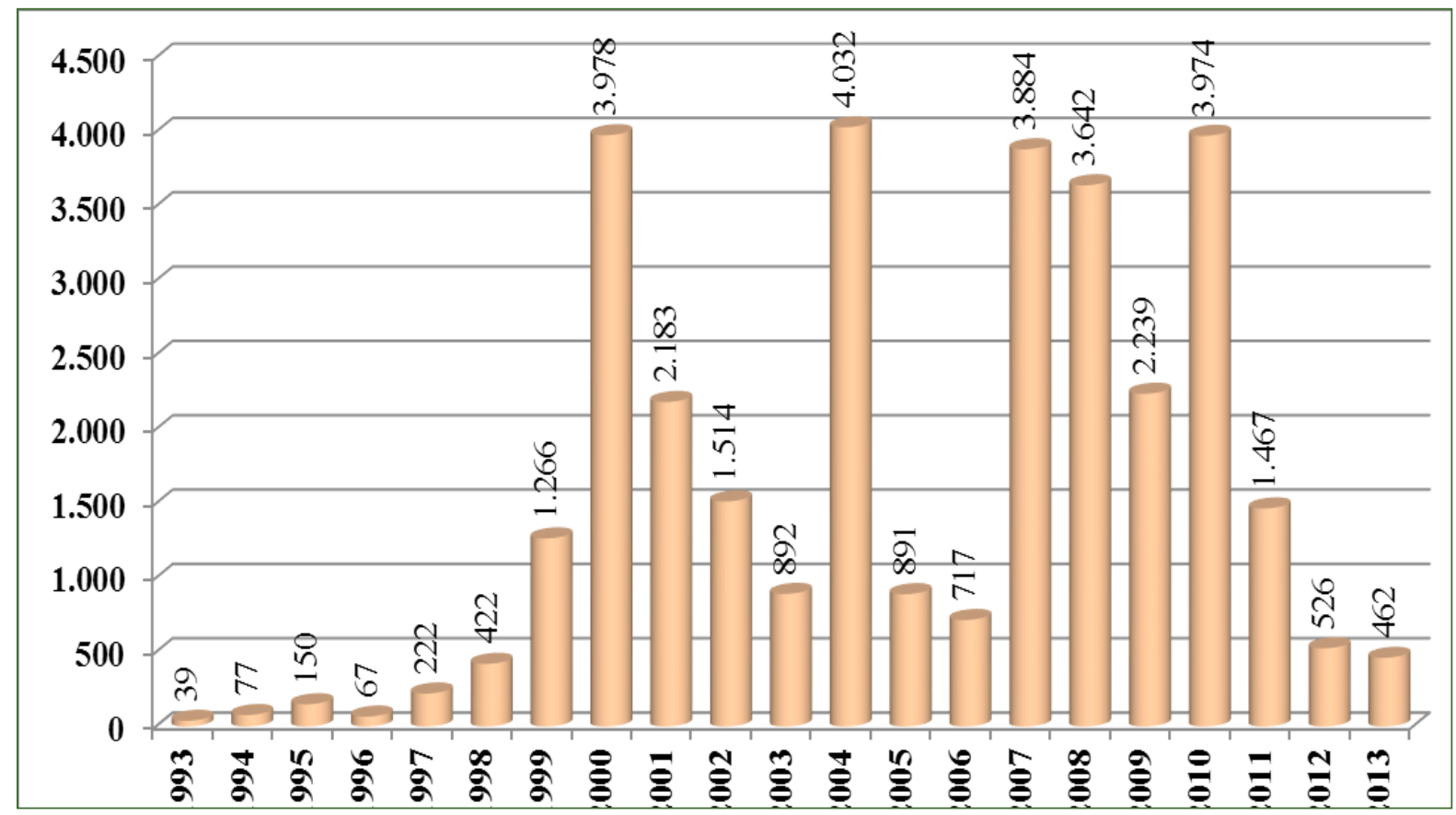

Figura 4. Evolución de la inversión directa de España en México, 1993-2013 (Millones de euros). Fuente: Secretaría de Estado de Comercio. Datalnvex.

En contraste, las sumas invertidas fueron muy superiores en el periodo 20012007, con una inversión media por año de 2.016,2 millones de euros y un monto total de 14.113,7 millones de euros equivalentes al 43,23 por ciento de la inversión total del periodo 1993-2013. Es importante resaltar los dos picos de inversión de los años 2004 y 2007, de 4.032 y 3.883,8 millones de euros, respectivamente (figura 4). El primero correspondió a la consolidación de las inversiones españolas en los servicios financieros, seguros y fondos de pensión, en telecomunicaciones (telefonía móvil), en el sector energético -en donde las empresas ampliaron su participación hacia el subsector de las energías renovables- y en algunas ramas de la industria manufacturera (metalurgia, metalmecánica y fabricación de bebidas); el segundo pico, del año 2007, fue el reflejo no solo de que se mantuvieron los flujos de inversión hacia los sectores bancario e industrial, sino que también se diversificaron sus intereses hacia nuevas actividades como la construcción (obra civil e infraestructu-

55 Marchini, 2005, p. 9.

56 Secretaría de Economía, 2014b. 
ra), los servicios de esparcimiento y recreativos (casas de juego y casinos), los servicios turísticos (hostelería) e inmobiliarios, de apoyo a negocios y profesionales y el comercio $^{57}$.

Finalmente, en el periodo 2008-2013, resulta llamativo que, a pesar de la intensidad de la crisis económica desatada sobre España desde 2008, la inversión media anual en México fue la más alta de todo el periodo contemplado. En efecto, se destinaron 12.310,8 millones de euros, 37,71 por ciento del total y una media por año de 2.051,7 millones de euros, con dos picos máximos en 2008 y 2010 (3.641,6 y 3.974,2 millones de euros), manteniendo la tendencia del año 2007 en cuanto a los sectores, subsectores y ramas económicas a las que se dirigió la inversión (servicios financieros, seguros y fondos de pensión, ingeniería civil y construcción de edificios y telecomunicaciones, principalmente $)^{58}$. Cabe señalar el fuerte contraste que presentaron los montos de inversión entre el primer trienio o fase inicial de la crisis de la economía española y el segundo trienio marcado por la intensidad de la recaída en la crisis y la contracción total de la inversión directa dirigida hacia México, América Latina y el mundo en general (figura 4).

El cuadro 2 sintetiza la dirección de los flujos de las inversiones españolas en función del grado de interés que ofrecen los distintos sectores de actividad de la economía de México a lo largo de los tres subperiodos analizados. Como ya antes se señalaba, fueron actividades muy concretas del sector servicios las que polarizaron de forma muy destacada pero decreciente el grueso del capital invertido $(68,62 \%)$ y que mantuvo su preponderancia en los tres lapsos referidos. Le siguió muy por detrás la inversión en la industria de transformación $(22,47 \%)$, incrementada sobre todo en la fase 2001-2007; por su parte, las actividades vinculadas a la construcción de infraestructuras físicas y edificios $(8,90 \%)$ adquirieron un notable protagonismo a partir de 2008 con el 17,48 por ciento de la inversión de la fase 2008-2013. En contraste, las actividades primarias en ningún momento captaron inversiones relevantes.

\begin{tabular}{|l|r|r|r|r|r|r|r|r|}
\hline \multirow{2}{*}{$\begin{array}{c}\text { Sector de } \\
\text { actividad }\end{array}$} & \multicolumn{2}{|c|}{$\mathbf{1 9 9 3 - 2 0 0 0}$} & \multicolumn{2}{c|}{$\mathbf{2 0 0 1 - 2 0 0 7}$} & \multicolumn{2}{c|}{$\mathbf{2 0 0 8 - 2 0 1 3}$} & \multicolumn{2}{c|}{$\mathbf{1 9 9 3 - 2 0 1 3}$} \\
\cline { 2 - 9 } & \multicolumn{1}{c|}{ Inversión } & \multicolumn{1}{c|}{$\%$} & Inversión & \multicolumn{1}{c|}{ Inversión } & $\%$ & Inversión & $\%$ \\
\hline Primario & 2 & 0,0 & 3 & 0,0 & 1 & 0,0 & 6 & 0,0 \\
Industria & 1.172 & 18,8 & 5.060 & 35,9 & 1.102 & 9,0 & 7.334 & 22,5 \\
Construcción & 71 & 1,1 & 682 & 4,8 & 2.152 & 17,5 & 2.904 & 8,9 \\
Servicios & 4.976 & 80,0 & 8.369 & 59,3 & 9.056 & 73,6 & 22.401 & 68,6 \\
\hline Total & $\mathbf{6 . 2 2 0}$ & $\mathbf{1 0 0 , 0}$ & $\mathbf{1 4 . 1 1 4}$ & $\mathbf{1 0 0 , 0}$ & $\mathbf{1 2 . 3 1 0}$ & $\mathbf{1 0 0 , 0}$ & $\mathbf{3 2 . 9 4 5}$ & $\mathbf{1 0 0 , 0}$ \\
\hline
\end{tabular}

Cuadro 2. Inversión directa de España en México por sector de actividad, 1993-2013

(Millones de euros).

Fuente: Secretaría de Estado de Comercio. Datalnvex. 
El cuadro 3 detalla las ramas de actividad a que se destinaron las inversiones españolas considerando el periodo 1993-2013 en su conjunto. La primera evidencia es que fueron muy pocas las ramas económicas a las que se dirigió el volumen principal de la inversión. Únicamente 14 ramas de actividad ${ }^{59}$ atrajeron más del uno por ciento de la inversión española total. En conjunto estas 14 ramas aportaron más del 90 por ciento de la inversión española directa total de 32.644,8 millones de euros del periodo señalado.

No obstante, como ya se señalaba, a lo largo del periodo analizado se observaron diferencias notables entre las ramas de actividad tanto en el volumen de inversión realizada como en su distribución en el tiempo. Siete de ellas mantuvieron en todo el periodo un nivel inversor regular, superior al $1 \%$ de la inversión española total y en conjunto concentraron el 67,90 por ciento de la misma (cuadro 4). Más específicamente, la rama de servicios financieros tuvo un protagonismo extraordinario en el proceso inversor de España en México pues representó más del 37,67 por ciento de la inversión final e incluso superó el 56,50 por ciento en el periodo inicial de 19932000. De hecho, dos instituciones bancarias de origen español, -BBVA Bancomer y Banco Santander- controlaban en conjunto el 40 por ciento de los activos bancarios en México, según la Comisión Nacional Bancaria y de Valores con información reportada en mayo de $2013^{60}$. La misma fuente señalaba que BBVA Bancomer era la institución bancaria que más clientes atendía en todo el país (más de 20 millones de usuarios). Ambas instituciones financieras adquirieron varios bancos mexicanos y los fusionaron; el Grupo BBVA Bancomer, con presencia en México a partir de 2000, adquirió los bancos mexicanos Bancomer, Mercantil, Probursa, Oriente, Cremi y Banco Unión, en tanto que Grupo Financiero Santander, con más de 9 millones de clientes, inició sus actividades en México en 1997 luego de comprar los bancos Mexicano y Serfín ${ }^{61}$.

59 La fuente de información de datos DataInvex diferencia hasta 88 ramas de actividades empresariales con inversión exterior, según la Clasificación Nacional de Actividades Económicas (CNAE) de 2009.

60 Cita tomada de Esquivel, 2013.

61 Ibid.; Solana, 2012, p. 125-126 y 129. 


\begin{tabular}{|l|r|r|}
\hline \multicolumn{1}{|c|}{ Ramas de actividad } & Inversión & \% del total \\
\hline 64 Servicios Financieros, excepto Seguros y Fondos Pensiones & 12.298 & 37,7 \\
\hline 61 Telecomunicaciones & 3.500 & 10,7 \\
\hline 35 Suministro de Energía Eléctrica, Gas, Vapor y Aire & 2.913 & 8,9 \\
\hline 65 Seguros, Reaseguro, Fondos Pensión, excepto S.Social & 2.105 & 6,4 \\
\hline 42 Ingeniería Civil & 1.950 & 6,0 \\
\hline 24 Metalurgia; Fabricación Productos Hierro, Acero & 1.323 & 4,1 \\
\hline 11 Fabricación de Bebidas & 1.084 & 3,3 \\
\hline 55 Servicios de Alojamiento & 1.071 & 3,3 \\
\hline 41 Construcción de Edificios & 868 & 2,7 \\
\hline 23 Fabricación de otros Productos Minerales no Metálicos & 834 & 2,6 \\
\hline 46 Comercio Mayor e Interme. Comercio, excepto Vehículos Motor & 465 & 1,4 \\
\hline 52 Almacenamiento y Actividades Anexas al Transporte & 359 & 1,1 \\
\hline 92 Actividades de Juegos de Azar y Apuestas & 349 & 1,1 \\
\hline 68 Actividades Inmobiliarias & 343 & 1,0 \\
\hline Subtotal de las 14 ramas & 29.463 & 90,3 \\
\hline Resto de las ramas & 3.182 & 9,8 \\
\hline Inversión total & $\mathbf{3 2 . 6 4 5}$ & $\mathbf{1 0 0 , 0}$ \\
\hline
\end{tabular}

Cuadro 3. Ramas de actividad con una inversión superior al 1\% de la inversión española total, 1 993-2013 (Millones de euros y \%).

Fuente: Secretaría de Estado de Comercio. Datalnvex.

\begin{tabular}{|l|r|}
\hline \multicolumn{1}{|c|}{ Ramas de actividad } & Inversión \\
\hline 64 Servicios Financieros, excepto Seguros y Fondos Pensiones & 12.298 \\
61 Telecomunicaciones & 3.500 \\
35 Suministro de Energía Eléctrica, Gas, Vapor y Aire & 2.913 \\
11 Fabricación de Bebidas & 1.084 \\
55 Servicios de Alojamiento & 1.071 \\
23 Fabricación de otros Productos Minerales no Metálicos & 834 \\
46 Comercio Mayor e Interme. Comercio, excepto Vehículos Motor & 465 \\
\hline Subtotal de las 7 ramas & 22.166 \\
\hline \% de la inversión total & $\mathbf{6 7 , 9}$ \\
\hline
\end{tabular}

Cuadro 4. Ramas de actividad con una inversión superior al 1\% de la inversión española total en los tres periodos analizados (Millones de euros).

Fuente: Secretaría de Estado de Comercio. Datalnvex. 
El protagonismo de la inversión española fue también relevante en las ramas de telecomunicaciones ( $10,72 \%$ total), energía eléctrica y gas ( $8,92 \%)$. Estas tres ramas económicas aportaron en conjunto el significativo 57,31 por ciento de la inversión final (cuadro 4). En la rama de telecomunicaciones, destacó la llegada de la empresa Telefónica México en 2001, la cual inició sus operaciones en el área de telefonía móvil y actualmente concentra el $25 \%$ del mercado nacional, siendo el segundo operador más importante del país en este rubro; además, en 2010 se asoció con las empresas Televisa y Megacable para formar el consorcio G-Tac (Grupo de Telecomunicaciones de Alta Capacidad) a fin de operar redes de fibra óptica de la Comisión Federal de Electricidad; asimismo, la empresa española WL Comunicaciones participó en el tendido de cableado de fibra óptica en el Valle de México, donde se ubica la mayor concentración de población del país. Por su parte, el Grupo PRISA compró acciones de radiodifusoras propiedad de Televisa Radio (50\% de las acciones del Grupo Radiópolis).62

En la rama energía eléctrica y gas cabe resaltar, en primer lugar, el arribo de las empresas Iberdrola y Unión Fenosa, que iniciaron sus actividades en México en 1984 y 1997, respectivamente; ambas empresas participaron en el grupo de "Productores Independientes de Energía", modalidad de inversión privada en electricidad aprobada en la Ley del Servicio Público de Energía Eléctrica (LSPEE) luego de su reforma en diciembre de $1992^{63}$. Estas empresas intervinieron en la construcción y operación de varias centrales eléctricas de ciclo combinado en México $^{64}$ para la venta de electricidad a la Comisión Federal de Electricidad (CFE), así como en la construcción de gasoductos para su abastecimiento. Por su parte, la empresa Abengoa inició sus actividades en México desde 1982 haciendo obras electromecánicas principalmente para el ramo hostelero, pero a partir de 1991 inició la construcción de subestaciones y líneas de transmisión para la CFE; para mediados de 2013 había desarrollado 2.600 kilómetros de infraestructura para el transporte de energía eléctrica, además de construir la central de cogeneración más grande del país para Petróleos Mexicanos (PEMEX). ${ }^{65}$ Asimismo, la empresa Elecnor con presencia en México desde 1992, desarrolló dos grandes proyectos: una central de ciclo combinado en el estado de Sonora, y un gasoducto en el estado de Morelos, este último en asociación con Enagás, firma también española. ${ }^{66}$

Otras empresas españolas que participaron en el sector energético mexicano son Repsol y Gas Natural Fenosa. La primera ganó en 2003 la licitación para perforar pozos y realizar la extracción de gas natural seco en el bloque más extenso de los

62 Esquivel, 2013; Solana, 2012, p.190.

63 D.O.F., 13 de diciembre de 1992. De acuerdo con esta ley, fueron aprobadas seis modalidades de participación del capital privado en el sector eléctrico en México: Productor Independiente de Energía, Autoabastecimiento, Cogeneración, Pequeña Producción, Importación y Exportación.

64 Iberdrola es el primer generador privado en México, con una capacidad instalada de $5.000 \mathrm{MW}$, de los cuales 4.300 MW corresponden a la modalidad de productor independiente de energía y $700 \mathrm{MW}$ a las de autoabastecimiento y cogeneración. Solana, 2012, p. 161.

65 Abengoa México, 2014.

66 Urdiales, 2013. 
nueve que integran la denominada Cuenca de Burgos, región de yacimientos de gas ubicada al noreste del país en la frontera con Estados Unidos, a través de los denominados Contratos de Servicios Múltiples (CSM) ${ }^{67}$. Por su parte, Gas Natural Fenosa, filial de Repsol, es el principal operador de gas natural de México y desde 1997 obtuvo permisos para la distribución de gas a consumidores residenciales e industriales en las zonas metropolitanas de México, Monterrey y Toluca, las ciudades del Bajío, y las de Nuevo Laredo y Saltillo-Ramos Arizpe-Arteaga, todas ellas entre las de mayor dinamismo económico de México. Actualmente cuenta con 1.300 .000 clientes y con una red de distribución de gas natural de alrededor de 16.468 kilómetros.

En el ramo de las energías renovables, varias empresas españolas fueron ganando terreno en el mercado mexicano. Iberdrola, a través de su filial Iberdrola Solar, construyó en 2007 el primer parque eólico privado del país en Oaxaca, en la región del istmo de Tehuantepec, que es la zona con mayor potencial eólico del país, y para 2012 había construido dos parques más en la misma zona ${ }^{68}$. Asimismo, la empresa Acciona, que opera en México desde 2009, es la principal productora de energía renovable, con cuatro parques de su propiedad también en el istmo de Tehuantepec (556,5 MW). Renovalia Energy, esta última a través de su filial en México Desarrollos Eólicos Mexicanos (Demex), así como Endesa (a través de Enel Green Power), Gamesa, Gas Natural Fenosa y Preneal fueron otras empresas que realizaron inversiones en plantas de energía eólica en el istmo oaxaqueño; por su parte, Abengoa Solar actualmente desarrolla proyectos de energía termosolar en el estado de Sonora, al norte de México, mientras Gestamp Renewables construye pequeñas centrales hidroeléctricas, parques eólicos e instalaciones fotovoltaicas en los estados de Jalisco, Guanajuato, Zacatecas y Durango, en el centro-occidente y centro-norte del país ${ }^{69}$.

Las otras siete ramas de actividad con inversión superior al uno por ciento entre 1993 y 2013, presentaron la singularidad de que en alguno de los tres periodos analizados no alcanzaron el uno por ciento de la inversión española total. Por ejemplo, la rama de seguros, reaseguros y fondos de pensiones $(6,15 \%)$ alcanzó una sólida presencia en México gracias a las inversiones de las fases 1993-2000 y 2008-2013, en contraste, la rama de metalurgia, fabricación de productos de hierro y acero $(4,05 \%)$ redujo la participación de su inversión en la fase 2008-2013 al no alcanzar el uno por ciento de la inversión total. Por su parte las ramas construcción de edificios $(2,66 \%)$ e ingeniería civil $(5,97 \%)$ asentaron su vigorosa presencia en las dos últimas fases al igual que la rama de actividades inmobiliarias (1,05\%) a la que están vinculadas.

La rama de seguros, reaseguros y fondos de pensiones constituye una extensión de las actividades de los grupos financieros BBVA Bancomer y Santander, además de Mapfre, ésta última con presencia en América Latina a partir del decenio de 1990. En el caso de la rama de metalurgia y fabricación de productos de hierro y acero, se encontraron en México alrededor de treinta empresas, entre las que destacan las que producen maquinaria y equipo industrial y agrícola, estructuras metálicas para la

67 PEMEX, 2013.

68 Solana, 2012, p. 162-163.

69 Sánchez-Salazar, Alonso y Casado, 2007; Esquivel, 2013; Sánchez-Salazar y Casado, 2014; Raso, 2014. 
construcción, herramientas, compresores, moldes, y otros productos de la industria metalmecánica.

Por su parte, las empresas de las ramas de construcción e ingeniería civil experimentaron un auge muy importante en México sobre todo a partir de finales del decenio de 1990 y el inicio del siglo XXI, de manera que el número de las más relevantes se aproximó a 60. Sobresale la presencia de empresas como OHL, que se ha enfocado al desarrollo de importantes proyectos de construcción de vías terrestres y edificación civil e industrial, y a la operación de infraestructura de transporte en concesión, que incluye autopistas urbanas, carreteras y aeropuertos ${ }^{70}$; además de otras como Abantia Ticsa, vinculada al sector energético a través de mantenimiento a centrales eléctricas y construcción de instalaciones para el tratamiento de gas natural junto a los pozos de extracción; Aqualia Infraestructuras, especializada en la construcción de obras hidráulicas y acueductos en el centro y centro-norte del país; ACS, que a través de sus filiales ha desarrollado proyectos en los sectores industrial y energético de refinación, petroquímica y electricidad; Duro Felguera, que también realizó obras de ampliación en los complejos de PEMEX y en Altos Hornos de México en el sureste y norte del país; CAF, que a partir de 1992 realizó obras de rehabilitación, mantenimiento y ampliación en el metro de las ciudades de México y Monterrey, además de obtener la concesión para operar el Tren Suburbano de la Zona Metropolitana del Valle de México y establecer una planta para la construcción de trenes para el metro ${ }^{71}$; IDOM Ingeniería y Consultoría, cuya actividad se enfocó hacia proyectos de ordenación urbana, obras portuarias y de infraestructura energética; e Ingenor Siglo XXI que ha construido complejos residenciales en Guadalajara y un gran desarrollo habitacional ( 17 mil viviendas) en Playa del Carmen, en la Riviera Maya, entre muchas otras.

En la rama de actividades inmobiliarias, también figuran empresas del grupo OHL en el área de desarrollos turísticos, así como filiales de los grandes grupos hoteleros (Meliá, Riú, Iberostar, Excellence-Resorts, Sandos, Paradisus, Catalonia, NH, Occidental, Barceló, Four Seasons, entre otros). ${ }^{72}$

Finalmente, la rama de almacenamiento y actividades anexas al transporte $(1,10 \%)$, concentró la mayor parte de su inversión tan sólo en la fase inicial 19932000 y como empresas representativas por su presencia en México sobresalen Iberia en transporte aéreo, Global Vía Infraestructuras, en la administración de concesiones de infraestructura (puentes, carreteras), ADIF en transporte ferroviario y Sparber Líneas Marítimas y Vitransgroup International, en sistemas de fletes internacionales. Por su parte, la rama de actividades de juegos de azar y apuestas (1,07\%)

70 La actividad de OHL se remonta al decenio de los 80 en que inicia proyectos de construcción en Cancún, la Ciudad de México y Monterrey. Entre las obras más importantes en este rubro destacan los aeropuertos de Oaxaca y Puerto Escondido, en el estado de Oaxaca, y el hotel Meliá y el Desarrollo Turístico Mayakoba en la Riviera Maya, entre otros, así como la construcción, administración y operación de seis autopistas de peaje en los estados de México, Distrito Federal (autopista urbana), Puebla y Veracruz, y del aeropuerto internacional de la ciudad de Toluca. Solana, 2012, p. 177-180.

71 Ibíd., p. 137-138.

72 Mercamétrica, 2014; ICEX, 2012 y 2014. 
adquirió protagonismo superior al uno por ciento de la inversión únicamente en la fase 2008-2013, a través de la empresa Codere, que en 1998 se asoció con CIE y el grupo Caliente, consolidándose como líder en el juego privado con presencia en varias ciudades de México; así como de la Administradora Hipódromo de Las Américas. ${ }^{73}$

Además de estas 14 ramas de producción con inversión superior al uno por ciento de la realizada de 1993 a 2013, hay algunas otras que no alcanzando esta proporción en todo el periodo de estudio, sí lo consiguieron en alguna de las tres fases o etapas en las que se dividió el periodo de estudio. Es el caso de las ramas de fabricación de otros productos minerales no metálicos (3,70\%); actividades auxiliares a los servicios financieros $(2,44 \%)$ e industria química $(1,59 \%)$ en la fase 1993-2000. En la etapa 2001-2007, alcanzaron el 1\% del total las ramas industria textil (2,00\%); venta y reparación de vehículos de motor (1,42\%); fabricación de vehículos de motor y remolques ( $1,07 \%)$ y transporte terrestre y por tubería ( $1,05 \%$ ). Por último, en la fase temporal más reciente 2008-2013, estuvieron presentes las ramas actividades jurídicas y de contabilidad $(3,53 \%$ ) y programación, consultoría y otras actividades relacionadas (1,04\%). En este último grupo figuran un gran número de empresas orientadas hacia los servicios de consultoría y administración de gestión, servicios de telecomunicaciones e informática y otros servicios para las empresas.

En resumen, sobre un potencial de 88 ramas de inversión exterior que presenta la CNAE-2009, tan solo 23 fueron las ramas económicas que bien de forma regular, bien en alguna de las tres fases establecidas, aportaron un volumen de inversión por encima del uno por ciento del total de la inversión directa española dirigida a México; no obstante, hay que destacar que casi el setenta por ciento $(69,73 \%)$ de la inversión realizada de 1993 a 2013 corresponde a la suma de las cinco ramas de actividad más importantes.

\section{Distribución geográfica de la inversión directa de España en México. ${ }^{74}$}

La inversión directa de España en México en el periodo 1999-2013 fue de 33.180,7 millones de euros que representó el 0,33\% del PIB total en dicho periodo (cuadro 5). La distribución geográfica de dicha en el periodo analizado es un reflejo de las diferencias económicas existentes al interior del país (figuras 5 y 6). Más de las cuatro quintas partes $(26.989,2 \text { millones de euros })^{75}$ de la inversión española total acumulada del periodo 1999-2013 se concentró en el Distrito Federal (DF), sede de la capital de la República; por lo mismo, gran parte de las empresas extranjeras

74 La información estadística para el análisis de la inversión española en México por entidad federativa y sectores de actividad económica, cuya fuente oficial es la Secretaría de Economía de México, sólo se encuentra disponible a partir del año 1999. Por esa razón no pudieron incluirse los datos del periodo 1993-1998.

75 Los datos de inversión de la Secretaría de Economía del gobierno de México se computan en dólares USA y han sido transformados a euros al valor de cambio oficial (1,2638 dólares por euro) del 13 de octubre de 2014 , última fecha de consulta de la fuente. 
establecidas en el país ubican sus oficinas centrales en esta unidad administrativa, también debido a las facilidades y servicios que ofrece, y porque la Zona Metropolitana del Valle de México (ZMVM) -que abarca además del Distrito Federal parte de los estados vecinos de México e Hidalgo- ${ }^{76}$ representa el mayor mercado del país $(20,4 \text { millones de habitantes })^{77}$. De hecho, el DF es la única entidad federativa en la que la IED de España rebasó el $1 \%$ del PIB de dicha entidad para el periodo referido ( $1,49 \%$; cuadro 5$)$.

Muy atrás del Distrito Federal le siguieron los estados de Nuevo León, sede del centro económico más importante de la región noreste, y el estado de México, como parte de la ZMVM; ambos fueron los estados con mayor desarrollo industrial del país; no obstante, en ambos casos la IED de España participó con porcentajes del PIB estatal respectivo inferiores al promedio nacional, alcanzando apenas 0,3 y $0,15 \%$ respectivamente, en todo el periodo señalado. Otros tres estados, Jalisco en el centro-occidente, Quintana Roo en el sureste y Puebla en el centro, atrajeron inversiones en el rango de 476 a 637 millones de euros que representaron del 1,4 al 1,9 por ciento de la inversión española total. En Jalisco y Puebla, la inversión española representó 0,1 y $0,14 \%$ del PIB estatal respectivo del periodo, y llama la atención el caso de Quintana Roo, entidad cuya economía se basa en el turismo, porque la presencia de IED de España en su territorio es realmente significativa, al representar el $0,35 \%$ del PIB estatal del periodo, segunda proporción más alta entre las entidades federativas, después del DF. Lo anterior significa que solo seis estados que en conjunto concentraron el 45,3 por ciento del PIB nacional, ${ }^{78}$ reunieron el 97 por ciento de la inversión española total acumulada en el periodo 1999-2013, de los cuales uno es la capital, cinco congregan la mayor actividad industrial del país y uno contiene al corredor turístico más dinámico de las últimas décadas (Cancún y la Riviera Maya).

76 SEDESOL-CONAPO-INEGI, 2012.

77 INEGI, 2011. Fue por esta razón que una parte importante de la IED se registró en el DF, aunque su aplicación real se haya concretado en otras partes del país.

78 INEGI, 2012. 


\begin{tabular}{|c|c|c|c|c|c|}
\hline $\begin{array}{l}\text { Entidades } \\
\text { federativas }\end{array}$ & \begin{tabular}{|c|} 
PIB 1999-2013 \\
(Millones de euros) \\
\end{tabular} & \begin{tabular}{|c} 
IED España 1999-2013 \\
(Millones de euros)
\end{tabular} & $\begin{array}{c}\text { Población total } \\
2010 \\
\end{array}$ & $\begin{array}{c}\text { \% de la IED de España } \\
\text { respecto al PIB }\end{array}$ & $\begin{array}{c}\text { IED per cápita } \\
\text { (Euros) }\end{array}$ \\
\hline Aguascalientes & 111.234 & 8 & 1.184 .996 & 0,01 & 6 \\
\hline Baja California & 315.058 & 92 & 3.155 .070 & 0,03 & 29 \\
\hline Baja California Sur & 71.455 & 76 & 637.026 & 0,11 & 119 \\
\hline Campeche & 474.806 & 3 & 822.441 & 0,00 & 4 \\
\hline Coahuila & 325.661 & 4 & 2.748 .391 & 0,00 & 1 \\
\hline Colima & 57.542 & 2 & 650.555 & 0,00 & 3 \\
\hline Chiapas & 177.460 & -13 & 4.796 .580 & $-0,01$ & -3 \\
\hline Chihuahua & 312.034 & -146 & 3.406 .465 & $-0,05$ & -43 \\
\hline Distrito Federal & 1.817 .447 & 26.989 & 8.851 .080 & 1,49 & 3.049 \\
\hline Durango & 123.805 & -4 & 1.632 .934 & 0,00 & -3 \\
\hline Guanajuato & 378.371 & 237 & 5.486 .372 & 0,06 & 43 \\
\hline Guerrero & 156.105 & 22 & 3.388 .768 & 0,01 & 6 \\
\hline Hidalgo & 155.180 & -5 & 2.665 .018 & 0,00 & -2 \\
\hline Jalisco & 636.866 & 635 & 7.350 .682 & 0,10 & 86 \\
\hline Estado de México & 930.010 & 1.383 & 15.175 .862 & 0,15 & 91 \\
\hline Michoacán & 233.008 & 23 & 4.351 .037 & 0,01 & 5 \\
\hline Morelos & 123.085 & 81 & 1.777 .227 & 0,07 & 45 \\
\hline Nayarit & 64.085 & 63 & 1.084 .979 & 0,10 & 58 \\
\hline Nuevo León & 706.365 & 2.148 & 4.653 .458 & 0,30 & 462 \\
\hline Oaxaca & 158.016 & 98 & 3.801 .962 & 0,06 & 26 \\
\hline Puebla & 329.595 & 476 & 5.779 .829 & 0,14 & 82 \\
\hline Querétaro & 188.107 & 166 & 1.827 .937 & 0,09 & 91 \\
\hline Quintana Roo & 148.664 & 513 & 1.325 .578 & 0,35 & 387 \\
\hline San Luis Potosí & 185.782 & 34 & 2.585 .518 & 0,02 & 13 \\
\hline Sinaloa & 208.848 & 35 & 2.767 .761 & 0,02 & 13 \\
\hline Sonora & 276.801 & -11 & 2.662 .480 & 0,00 & -4 \\
\hline Tabasco & 265.194 & 5 & 2.238 .603 & 0,00 & 2 \\
\hline Tamaulipas & 315.686 & 24 & 3.268 .554 & 0,01 & 7 \\
\hline Tlaxcala & 55.660 & 0 & 1.169 .936 & 0,00 & 0 \\
\hline Veracruz & 498.089 & 214 & 7.643 .194 & 0,04 & 28 \\
\hline Yucatán & 145.830 & 4 & 1.955 .577 & 0,00 & 2 \\
\hline Zacatecas & 92.130 & 24 & 1.490 .668 & 0,03 & 16 \\
\hline TOTAL MÉXICO & 10.037 .978 & 33.181 & 112.336.538 & $\mathbf{0 , 3 3}$ & 295 \\
\hline
\end{tabular}

Cuadro 5. Relación de la IED de España con el PIB y la población total de las entidades federativas de México, 1999-2013.

Fuente: INEGI, 2016; INEGI, 2011.

Nota: Tipo de cambio euro dólar: 1 euro $=1.2638$ dólares

Los tres estados siguientes, Querétaro, Guanajuato y Veracruz, atrajeron inversiones en el rango de 166 a 241 millones de euros ( 0,5 a 0,7\% de la inversión española total) y mientras los dos primeros mostraron un crecimiento industrial notorio en áreas innovadoras y competitivas, el último, Veracruz, alberga el polo petroquímico más importante del país (Coatzacoalcos-Minatitlán-Cosoleacaque). De estas tres entidades, la IED española representó una proporción significativa del PIB estatal solo en Querétaro $(0,14 \%)$. En los estados restantes, las inversiones españolas fueron poco representativas e incluso en cinco de ellos -Sonora, Chihuahua, Durango, Hidalgo y Chiapas-, se presentó un proceso de desinversión, probablemente relacionado con la crisis económica española; lo anterior se confirma al observar las ínfimas proporciones del PIB de los estados respectivos que representan las inversiones procedentes de España (cuadro 5).

El cuadro 5 también refiere la relación entre la IED de España en el periodo 1999-2013 y la población total de cada entidad federativa en 2010. A nivel nacional, 
la inversión española fue de 295 euros per cápita en el periodo señalado y solo tres entidades federativas mantuvieron una inversión por habitante superior al promedio del país. Destaca en particular el caso del DF, donde la inversión española rebasó los 3.000 euros per cápita (3.049 euros), cantidad que supera más de diez veces a la media nacional, debido a la concentración del registro de la IED en la capital del país. ${ }^{79}$ Por su parte, en Nuevo León y Quintana Roo la IED española equivale a 462 y 387 euros per cápita, cantidades notoriamente altas considerando que se trata de dos entidades en donde la industria y los servicios, en el primer caso, y el turismo, en el segundo caso, además de la construcción y los servicios inmobiliarios en los dos casos, son las actividades que más riqueza generan y la presencia del capital español es proporcionalmente alta con relación a la población. Lo mismo ocurre en Baja California Sur, entidad de vocación turística en donde la inversión de España es significativamente alta en este ramo y en los de la construcción y el inmobiliario con respecto al número de habitantes ( 119 euros per cápita). Las otras cuatro entidades, eminentemente industriales, con inversión española per cápita relativamente elevada son el estado de México, Querétaro, Jalisco y Puebla, con montos por habitante que oscilan entre 91 y 82 euros y a mayor distancia le sigue Nayarit, otra entidad con economía orientada hacia el turismo en el área de Bahía de Banderas, con una inversión de 58 euros per cápita. En el resto de las entidades federativas, la inversión española es inferior a 30 euros per cápita y en algunos estados como Chiapas, Hidalgo, Sonora y sobre todo Chihuahua el valor de la inversión per cápita es negativo como producto del ya mencionado fenómeno de desinversión muy probablemente asociado con el retiro de empresas debido a la crisis española y a procesos tales como el aumento en la actividad del crimen organizado en algunas entidades de la franja fronteriza norte.

Por su parte, la figura 6 muestra además la importancia relativa de la inversión española sobre el total de la IED recibida por cada entidad federativa. Llama la atención el caso de Oaxaca, estado que aunque solo recibió 97,8 millones de euros de inversión española en el periodo señalado, ésta representó el 40 por ciento de la IED absorbida. Destacan también Veracruz y Quintana Roo, con inversiones españolas del orden de 17 a 19,5 por ciento del total. En contraste, en un amplio grupo de estados, que son los de economía más dinámica ubicados en diversas partes del país, la IED fue elevada pero al mismo tiempo tuvo orígenes diversos, de manera que la inversión española mantuvo una importancia relativa menor (de 5,5 a 11\% de la total). El siguiente grupo de seis entidades, donde la inversión española representó de 1 a 4,5 por ciento, incluye a Baja California Sur, cuya economía está basada en el turismo dirigido sobre todo al mercado internacional, Querétaro y San Luis Potosí, con una industria vigorosa, y Sinaloa, Colima y Michoacán, cuya economía es diversificada con una base agroindustrial notable. En el resto de los estados la participación española en la IED total fue poco significativa (menor al 1\% del total). En este grupo se incluyeron los estados fronterizos del norte -Sonora, Coahuila y Tamau-

79 Ver primer párrafo de este apartado. 
lipas- en donde la competencia con las empresas de capital de EUA es acentuada; algunos del centro-norte -Durango, Zacatecas y Aguascalientes-, en donde la IED se dirigió en gran medida hacia la minería y procedió de Canadá principalmente (los dos primeros casos), o bien se orientó hacia la industria automotriz y fue originaria de Japón (el último caso); y otras entidades del centro -Hidalgo y Tlaxcala- y del sureste -Chiapas, Tabasco y Yucatán-, en general estados donde la IED total fue insignificante por el escaso atractivo que representa el bajo desempeño económico general de estas entidades federativas en las ramas de actividad de interés para la IED española (centrales eléctricas, energías renovables, turismo de playa, servicios financieros, etc.).

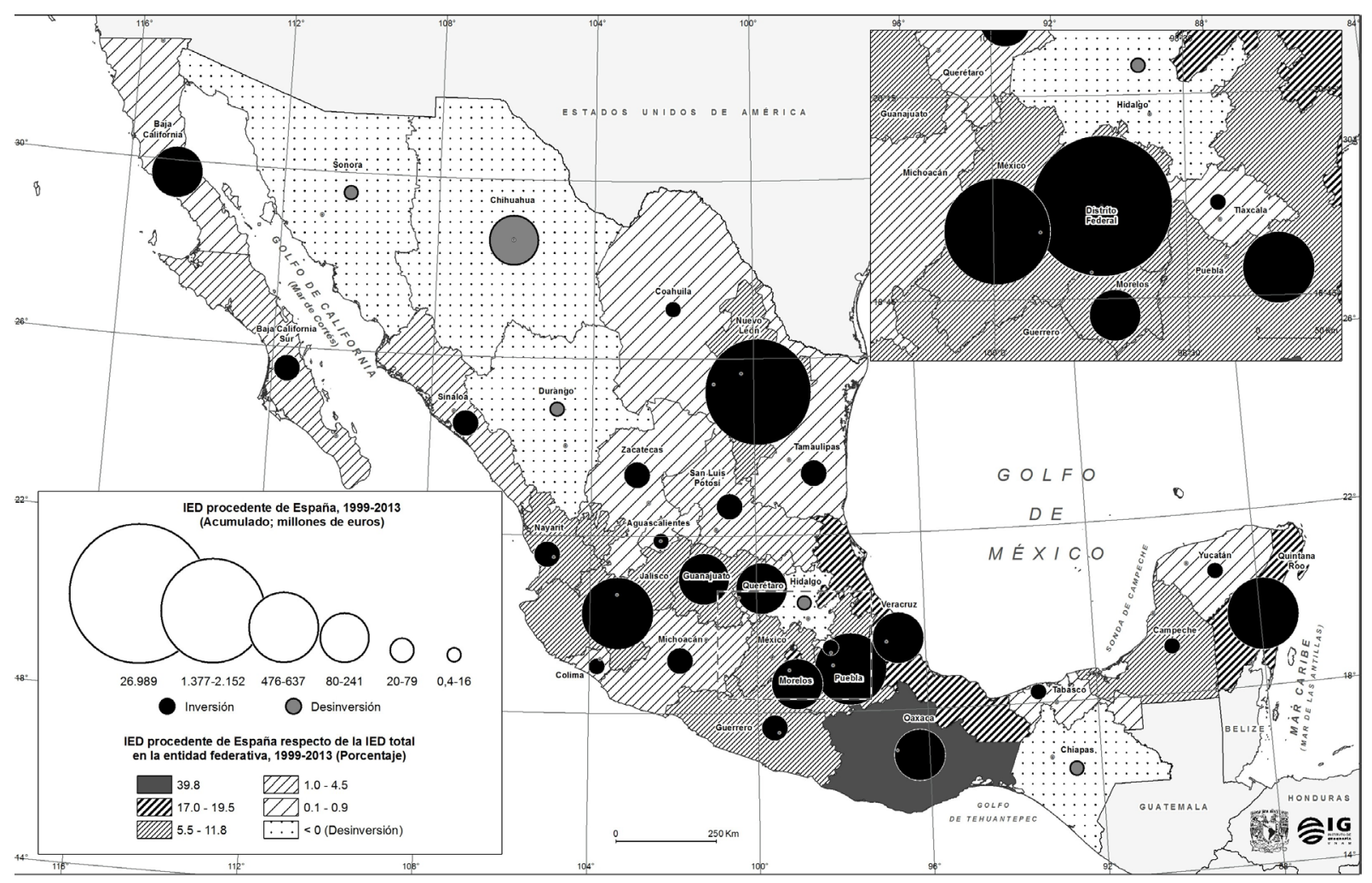

Figura 5. Monto e importancia porcentual de la inversión española por entidad federativa, acumulado 1999-2013.

Fuente: Secretaría de Economía, 2014a. Elaboración propia. 


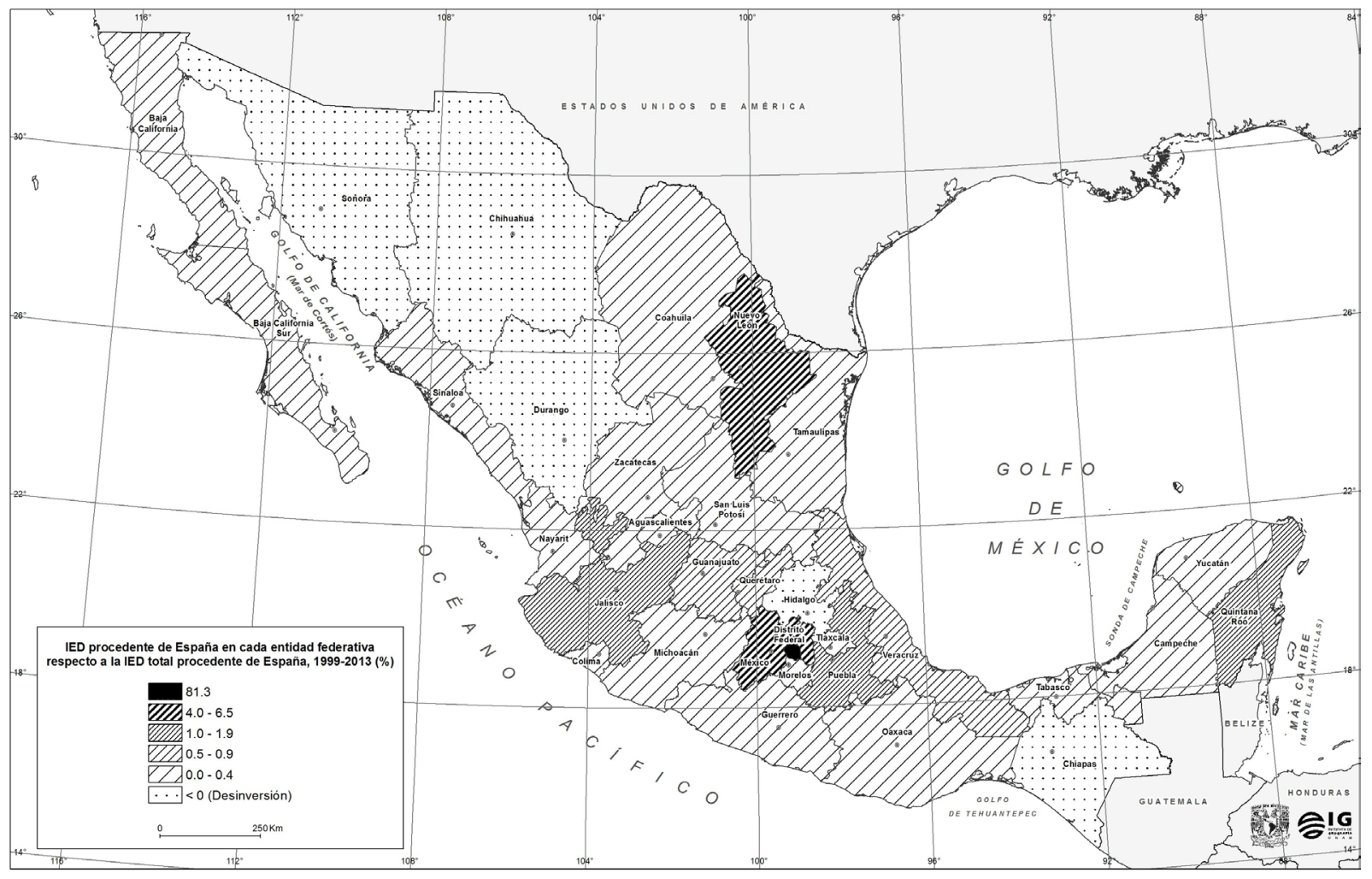

Figura 6. Distribución porcentual de la inversión española por entidad federativa, acumulado 1999-2013.

Fuente: Secretaría de Economía, 2014a. Elaboración propia.

\section{Distribución de la IED española por entidad federativa y sector de actividad}

La estructura de la inversión española por sectores de actividad económica, como anteriormente se había señalado, mostró una preponderancia nítida del sector terciario como el que más inversiones atrajo en el periodo (23.463 millones de euros; $70,7 \%$ ), seguido por el secundario (9.705 millones de euros; $29,3 \%$ ) y de manera apenas significativa, por el primario ( 13,4 millones de euros; $0,04 \%) .{ }^{80}$

La distribución geográfica de la inversión española por sectores de la economía se aprecia en la figura 7. Para el caso del sector primario (figura 7a), revela que sólo en tres entidades federativas, ésta representó más del uno por ciento de la inversión española total presente en cada estado: Sinaloa, con una agricultura capitalizada con fuerte orientación exportadora, obtuvo el porcentaje más alto $(28,3 \%)$, seguida por Michoacán y Campeche (12,4 y 9,7\%, respectivamente); en las siguientes nueve entidades -Chihuahua, Durango y Zacatecas, en el norte y centro-norte; Nayarit, Jalisco y Guanajuato, en el centro-occidente; Puebla y Veracruz en el centro y oriente; y Quintana Roo en el sureste-, si bien la inversión española en actividades primarias estuvo presente, representó menos del uno por ciento de la inversión total recibida de este país y estuvo dirigida a apoyar las actividades agropecuarias cuyo destino es

80 Secretaría de Economía, 2014a. 
el mercado nacional e internacional. En los 20 estados restantes la inversión española no existió, e incluso en un estado (Baja California), la hubo en algún momento pero se retiró, seguramente por la crisis y porque la cercanía con EE.UU. restó competitividad a las inversiones.

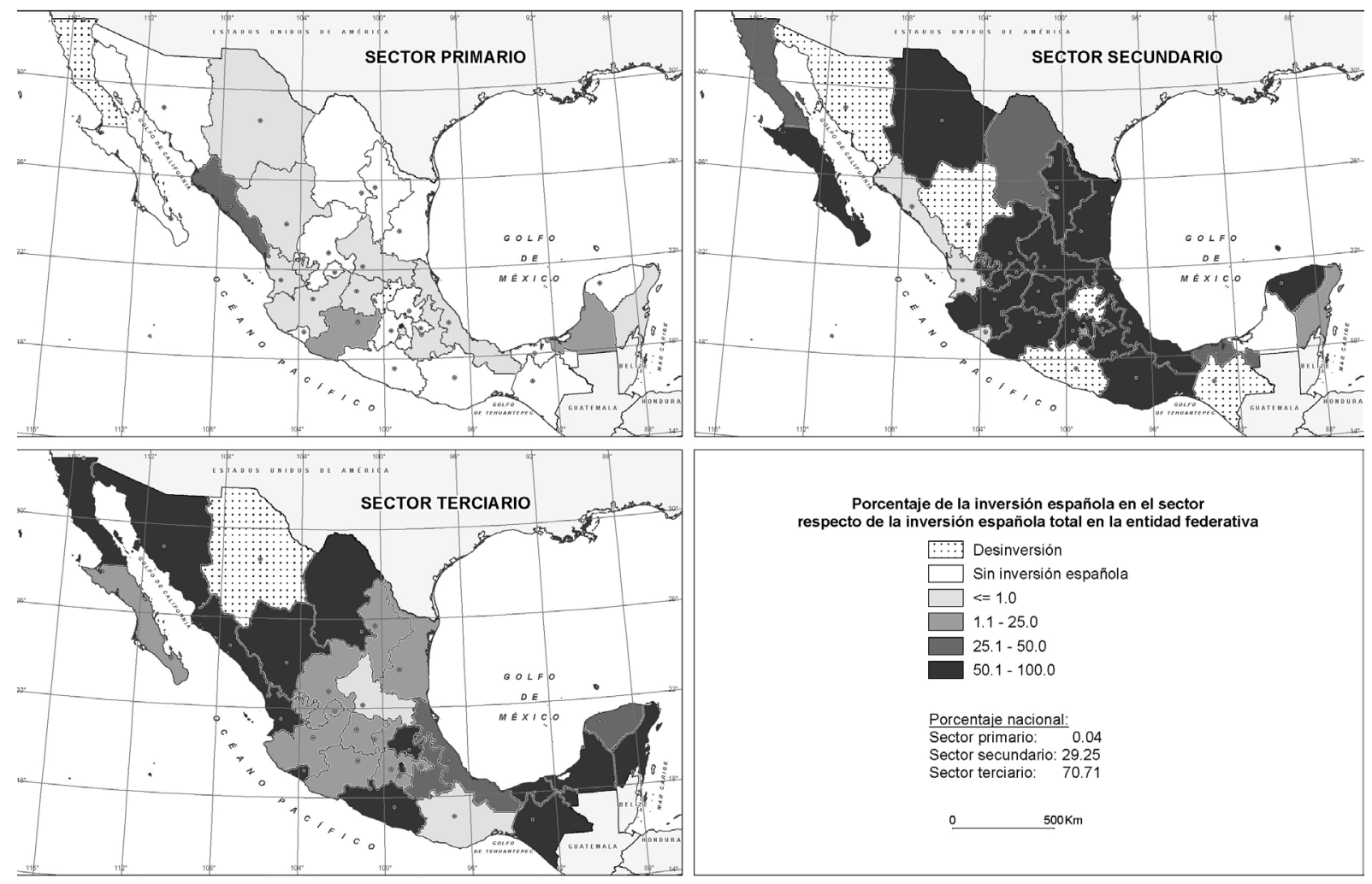

Figura 7a, 7b y 7c. Distribución porcentual de la inversión española en los sectores primario, secundario y terciario, por entidad federativa, acumulado 1999-2013.

Fuente: Secretaría de Economía, 2014a. Elaboración propia.

Por su parte, la inversión española en actividades secundarias -industria manufacturera, construcción y generación de energía, principalmente- mantuvo una presencia dominante respecto al total de la inversión española en la mayoría de los estados en donde se ubicó (figura 7b). En 18 de las 32 entidades federativas, rebasó el 50 por ciento de la inversión española total, y de ellas, en 15 estuvo por encima del 82 por ciento de dicha inversión, que es el reverso de lo que ocurre con los montos invertidos en el sector terciario en esos estados, cuya participación en el total es mínima (figura 7c). Solo en Veracruz, Puebla y Yucatán, la inversión en el sector secundario estuvo en el rango de 51 a 65 por ciento del total, debido a que el resto de la inversión fue atraída por el sector terciario de la economía. En la gran mayoría de las 18 entidades de este grupo -más de la mitad de los estados del país-, las inversiones se dirigieron a la industria manufacturera, ya sea en forma exclusiva o participando con otras ramas del sector secundario; tal es el caso de Baja California Sur, estado de 
México y Querétaro, en donde dichas inversiones se compartieron con la rama de la construcción, y en Jalisco y Nuevo León con la rama de la generación y distribución de energía. En los estados de Michoacán, Oaxaca y Veracruz no fue la industria manufacturera sino la construcción y la generación y distribución de energía las que atrajeron la inversión mientras en Tamaulipas, entidad fronteriza con EE.UU., fue exclusivamente la generación y distribución de energía la que absorbió el capital. El único caso en que la minería fue el sector más atractivo para las inversiones españolas en el periodo estudiado fue Zacatecas, entidad eminentemente minera y exportadora de plata. ${ }^{81}$ Sólo en tres estados, Baja California y Coahuila en el norte, y Tabasco en el sureste, la inversión española en el sector secundario quedó comprendida en el rango de 25 a 30 por ciento del total ${ }^{82}$ por competir principalmente con las empresas de EE.UU. y estuvo dirigida, en los dos primeros casos, a las ramas de la industria y la generación y distribución de energía, y a la rama de la construcción en el último caso, asociada al dinamismo y a la demanda de la industria petrolera. Por su parte, Quintana Roo y el Distrito Federal participaron con 24,5 y 18 por ciento de la inversión española en el sector, en las ramas de industria manufacturera y generación y distribución de energía, respectivamente. Por último, solo Sinaloa, Nayarit y Colima tuvieron menos del uno por ciento de inversión española en el sector por tratarse de estados poco industrializados mientras en Campeche el capital español estuvo ausente y cinco estados -Sonora, Durango, Hidalgo, Guerrero y Chiapas- sufrieron un proceso de desinversión (figura 7b).

Finalmente, el comportamiento espacial de la inversión española en el sector terciario, como ya se señalaba, fue contrario y complementario al del secundario (figura 7c). En 13 entidades federativas la inversión en este sector varió entre el 69 y el 100 por ciento de la total. En Baja California, la rama dominante fue la de servicios recreativos, que incluye a la subrama de los juegos de azar, por el atractivo que representa en este sentido el turismo fronterizo procedente de EE.UU.; en Campeche, Colima, Guerrero, Nayarit y Quintana Roo predominaron las inversiones en hostelería, aunque en este último caso también fueron relevantes los servicios inmobiliarios, asociados a esta última, y los de apoyo a negocios; en Sinaloa, Sonora e Hidalgo las inversiones se dirigieron al comercio, una actividad floreciente en las tres entidades federativas; en Coahuila, a los servicios inmobiliarios vinculados con el dinamismo industrial, y en Durango y Tabasco a los servicios profesionales y técnicos. Mención especial merece el Distrito Federal, el cual presentó la mayor diversificación de la inversión española en este sector, la cual se distribuyó, en orden de importancia, entre los servicios financieros, las telecomunicaciones, los servicios inmobiliarios, el comercio, los servicios de apoyo a negocios, los servicios profesionales y técnicos, y la hostelería. ${ }^{83}$ El siguiente grupo lo conforman 12 estados que concentraron del 1.1 al $25 \%$ de la inversión total de origen español en este sector. En Baja California Sur, por su marcada orientación económica hacia el turismo, las inversiones españolas se 
enfocaron hacia la hostelería y los servicios inmobiliarios ligados a la actividad turística, aunque no lograron competir en importancia con las procedentes de EE.UU. En las entidades fronterizas de Nuevo León y Tamaulipas, las inversiones españolas se dirigieron, en el primer caso a las telecomunicaciones, el comercio y los servicios de apoyo a negocios, por la importancia que tiene esta entidad al ser el asiento del centro regional del noreste del país en el primer caso, mientras en el segundo caso se orientó hacia los transportes y los servicios profesionales, científicos y técnicos. En los estados de Aguascalientes y Zacatecas en el centro-norte, la IED española se concentró en el comercio; en Jalisco, por albergar al centro regional del occidente del país, dicha inversión fue más diversificada y distribuida entre los servicios financieros y de seguros, el comercio, los servicios profesionales, científicos y técnicos, las telecomunicaciones, la hostelería y los servicios inmobiliarios, principalmente, en tanto que en Michoacán y Guanajuato, en la misma región, la inversión se orientó hacia el comercio y los servicios de apoyo a los negocios. Por su parte, en la región centro del país, el estado de México y Querétaro, por su mayor dinamismo económico, concentraron la inversión de origen español en la hostelería, los servicios inmobiliarios, los de apoyo a los negocios, los educativos y las telecomunicaciones. En contraste, en Tlaxcala y Morelos dichas inversiones se destinaron al comercio, y a los transportes y servicios inmobiliarios, respectivamente. Finalmente, en Oaxaca y San Luis Potosí, la inversión española en el sector terciario representó menos del 1\% de la total procedente de este país.

\section{Reflexiones finales}

La incorporación de España al grupo de países de referencia de la inversión internacional por haberse convertido, desde los años finales de la centuria pasada, en exportador neto de capitales, tiene en México a uno de sus socios más relevantes siendo el principal en América Latina. México, junto con Brasil, simboliza la solidez de la región como espacio estratégico de la internacionalización del capital español. En paralelo, las reformas acometidas por México para liberalizar la implantación del capital procedente del exterior y, en concreto, la firma del acuerdo de Libre Comercio con la Unión Europea en 2000, contribuyeron decididamente a fraguar una sólida relación con los países de la región, y con España en particular, que no ha dejado de incrementarse con los años motivada también por la afinidad cultural y lingüística producto de los lazos históricos, y en la actualidad, presenta claros indicios de ser potenciada debido a la reforma del sector energético decretada en diciembre de 2013 que garantiza su total liberalización, así como a los proyectos de grandes infraestructuras anunciados por la administración del presidente Peña Nieto.

La naturaleza e intensidad de la inversión llevada a México por las empresas españolas desde los años 90 de la centuria pasada confirman que la economía mexicana se ha convertido en uno de los pilares más sólidos y prometedores de la interna- 
cionalización de las mismas, a la vez que su participación es cada vez más decisiva en un mayor número y diversidad de actividades económicas -servicios financieros y banca, generación de electricidad y energías renovables, construcción, hostelería y servicios de consultoría y gestión, entre las más importantes- y ofrece expectativas de ser fortalecida en los próximos años.

Bien por la maduración del mercado nacional, bien por los agobios derivados de la grave crisis que sufre España desde 2008, bien por un poco de ambas causas, lo cierto es que las empresas españolas, incluidas las medianas y pequeñas, desde el inicio del decenio de 1990 han virado hacia la internacionalización de sus negocios, ocupando en el caso de México, un lugar privilegiado, pues sus inversiones se colocan apenas detrás de las procedentes de EUA en los años de los principales cambios estructurales en la economía mexicana, alternándose en el segundo puesto con la inversión originaria de los Países Bajos.

Los principales aportes de las empresas españolas en México que les han permitido expandir sus operaciones y diversificar sus áreas de negocio han sido precisamente las estrategias que les permitieron internacionalizarse: un entorno empresarial más competitivo en España y en Europa frente a un mercado menos maduro en el caso de México, la capacidad financiera de las grandes empresas españolas frente a las empresas mexicanas, generalmente más pequeñas (esto es más evidente en el ramo de la construcción de grandes infraestructuras ${ }^{84}$ su cultura empresarial y su know how, su capacidad de innovación y conocimiento con miras a mejorar los sistemas organizacionales y de planeación, la búsqueda de la mayor eficiencia y productividad, la capacitación del personal para la solución de problemas; todas ellas son circunstancias que explican la emergencia y potenciación de las inversiones españolas en ramas de actividad en donde han logrado competir con grandes ventajas con empresas nacionales y de otros países, como la construcción e ingeniería civil, el desarrollo de proyectos de generación eléctrica, en particular de energías renovables y los servicios de apoyo a las empresas, que incluyen actividades jurídicas, de consultoría, administración, gestión, logística, mercadotecnia, informática, telecomunicaciones y otras afines.

Para algunas de las grandes multinacionales españolas el mercado mexicano constituye una parte esencial, o cuanto menos sustancial de su actividad global, aunque obviamente dicha relevancia varía de empresa a empresa. Para muestra a continuación se señalan algunos de los ejemplos más relevantes de los beneficios que suponen las inversiones españolas para las empresas españolas y para México.

En el sector financiero los negocios mexicanos del Grupo BBVA constituyeron la parte esencial de sus beneficios para el año 2013 (81\%, con 1.805 millones de euros), lo que le permitió compensar las pérdidas experimentadas en su actividad inmobiliaria en España. Por su parte, para banco Santander su operación en México solo supuso el 10\% de su beneficio total (713 millones de euros), por debajo de Brasil 84 En este sentido, hay que recordar que los grandes proyectos requieren de grandes inversiones y que precisamente esa falta de capital por parte de las empresas mexicanas (aparte del know how) les impide participar de forma destacada en esos grandes proyectos. 
(23\%) pero por encima de España (7\%). Con un total de más de 3 mil 100 oficinas, ambos bancos ocupan un lugar destacado en el sector financiero mexicano (posición uno y tres en cuanto a depósitos), habiendo contribuido a intensificar y expandir geográficamente la bancarización en el país, así como al proceso de difusión de la banca electrónica ${ }^{85}$

Dentro del sector energético los proyectos mexicanos de Iberdrola representaron sólo el 5\% de sus beneficios brutos de operación (Ebitda; 382 millones de euros), pese a lo cual se constituye en el primer productor privado de electricidad en México con una producción de 34,700 GWh, casi una cuarta parte de la electricidad generada por la empresa, lo que sitúa a México en segundo lugar detrás de España. Ibedrola se convierte así en una de las principales beneficiadas de la apertura del sector eléctrico en México a la inversión extranjera. Como contraparte, la inversión ejercida por Ibedrola en México ha impulsado la modernización del sector eléctrico en el país a través de la construcción de centrales de ciclo combinado (más eficientes) en los estados del este y noreste del país, así como de centrales eoloeléctricas principalmente hacia la región del istmo de Tehuantepec en Oaxaca, en cuyo desarrollo también han participado las españolas Acciona y Gamesa ${ }^{86}$. Para esta última empresa su presencia en México resulta esencial al representar casi una cuarta parte de sus ventas ( 555 millones de euros). ${ }^{87}$

También en el sector energético, pero en este caso en el subsector del gas natural, la presencia de Gas Natural Fenosa ha permitido expandir el uso de este combustible en los hogares mexicanos frente al tradicional cilindro (bombona) de gas licuado de petróleo. Ello ha supuesto la construcción de una extensa red de distribución de gas (18 mil kilómetros) para llegar a 1,3 millones de clientes de las más importantes zonas urbano-industriales del país, aportando las operaciones de esta empresa en México casi el 7\% de su rendimiento bruto de explotación (349 millones de euros). ${ }^{88}$

En telecomunicaciones los ingresos obtenidos en México por Telefónica ( 1.596 millones de euros) apenas representaron el 2,8\%,89 habiendo tenido que enfrentar la posición de dominio que ejerce América Móvil (Telcel, propiedad de Carlos Slim) en el sector, por lo que su penetración ha sido menor que en otros países latinoamericanos como Argentina o Chile. Vale la pena mencionar que esta dificultad para penetrar en el mercado de la telefonía móvil mexicana también ha sido enfrentada por las demás compañías como Iusacell (ahora AT\&T) o Nextel. Pese a ello, los servicios de telefonía móvil que ofrece Telefónica cubren 93 mil localidades y más de 26.9 millones de clientes a lo largo de todo el país. ${ }^{90}$

85 Santander es superado por el Grupo Financiero Banamex perteneciente al consorcio financiero norteamericano Citigroup (BBVA, 2014; Santander, 2014).

86 Acciona ha incursionado también en el sector inmobiliario así como en la construcción de la planta depuradora de Atotonilco, la más grande del mundo.

87 Acciona, 2014; Gamesa, 2014; Iberdrola, 2014.

88 Gas Natural Fenosa, 2014.

89 Telefónica, 2014.

90 Telefónica, 2016. 
Las inversiones de Grupo Barceló en el tradicional sector hotelero de sol y playa han participado en la expansión de este sector hacia nuevas áreas geográficas del país: aparte de su destacada presencia en el Caribe mexicano (Cancún, Cozumel y la Riviera Maya) la compañía ha realizado importantes inversiones en la costa del Pacífico (Huatulco, Los Cabos, Manzanillo, Puerto Vallarta o Nuevo Vallarta) hasta aglutinar un total de 13 de sus 140 hoteles en México. También para Meliá México constituye un mercado relevante al aportar casi el $11 \%$ de sus ingresos operativos para 2013 ( 147 millones de euros). ${ }^{91}$

Pero sobre todo, México resulta esencial para la constructora OHL, entre otras grandes constructoras españolas que operan en el país, de donde obtiene el 74.6\% de sus rendimientos en 2013 (906 millones de euros) gracias principalmente a sus inversiones en la construcción y gestión de autovías de peaje en la Ciudad de México y su zona metropolitana, habiendo así facilitado la expansión de esta infraestructura ante una creciente demanda de uso del automóvil por parte de sus habitantes. ${ }^{92}$

Por último merece destacarse el rápido crecimiento que ha experimentado Inditex en México desde su llegada en 1992: a través de sus distintas marcas (Zara, Bershka, Pull \& Bear u Oysho, entre otras) su número de tiendas no ha parado de crecer, alcanzando las 98 en 2003 y 272 diez años después. ${ }^{93}$ Esta expansión ha sido paralela y ha fomentado nuevas formas de consumo asociadas a la difusión de centros comerciales que han modificado la imagen y la estructura urbana de las ciudades mexicanas.

Por todo lo anterior, se puede concluir que en la historia económica reciente, México y España nuevamente vuelven a estar vinculados y el resultado de esa asociación ha beneficiado a ambos países. En el caso de México las inversiones han contribuido a la modernización tecnológica del país, a la reactivación de sectores, subsectores y ramas económicas fortaleciendo la competitividad y los procesos de innovación, y a incrementar la eficiencia en la producción de bienes y servicios; en el caso de España, ha constituido una vía de internacionalización y crecimiento de sus empresas, y una alternativa para enfrentar la crisis económica iniciada a fines del decenio pasado. De ahí que sea previsible que el capital español siga consolidando su presencia en México en los próximos años.

\section{Bibliografía}

ABENGOA MÉXICO. Acerca de nosotros: historia. [En línea] <http://www.abengoamexico.com.mx/web/es/acerca_de_nosotros/historia/index.html> [15 de diciembre de 2014].

ACCIONA Informe anual 2013. 2014. [En línea] <http://memoria2013.acciona.

91 Grupo Barceló, 2014; Meliá Hotels International, 2014.

92 OHL, 2014.

93 Inditex, 2014. 
es/media/53991/Informe-Anual-2013-SPA.pdf>. [08 de junio de 2016].

AGUILAR, Alonso; BERNAL, Víctor M.; GUILLÉN, Arturo; VIDAL, Gregorio. El capital extranjero en México. México: Editorial Nuestro Tiempo. 1986. 253 p.

ALBEROLA, Enrique y LÓPEZ, Esther. La evolución de la inversión directa española en América Latina. Boletín Económico, Banco de España. Junio 2013. p. 61-69.

ARAHUETES, Alfredo. Las inversiones directas españolas en América Latina en el periodo 2001-2010, Anuario Iberoamericano, 2011. p. 67-85.

ARAHUETES, Alfredo y ELOZONDO, Carlos. La internacionalización de la empresa española. Estudio monográfico sobre el entorno económico y las oportunidades de inversión en México. Instituto de Crédito Oficial y Fundación Real. Instituto Elcano, Madrid. 2008. 192 p.

BBVA. Informe de gestión correspondiente al ejercicio 2013. Cuentas anuales consolidadas, informe de gestión e informe de auditoría correspondientes al ejercicio anual 2013. 2014. [En línea]. <accionistaseinversores.bbva.com/TLBB/fbinir/mult/Cuentas_Anuales_Informe_de_Gesti_n_e_Informe_de_auditor_a_Grupo_2013_tcm926-431317.pdf>. [20 de diciembre de 2014].

CASILDA, Ramón. La década dorada 1990-2000. Inversiones españolas directas en América Latina, Cátedra Grupo Santander. Madrid: Universidad Antonio de Nebrija, 2002. 22 p.

CASILDA, Ramón. Internacionalización e inversiones directas de las empresas españolas en América Latina 2000-2004. Situación y perspectivas. Serie: América Latina, $\mathrm{n}^{\circ}$ 5. Barcelona: CIDOB Edicions. Febrero 2005. 76 p.

CEPAL. Inversión extranjera en América Latina y el Caribe. Informes 1997-2007. Santiago de Chile: Comisión Económica para América Latina y el Caribe-Naciones Unidas. 1998-2008.

CEPAL. Inversión extranjera en América Latina y el Caribe. Informe 1999. Santiago de Chile: Comisión Económica para América Latina y el Caribe-Naciones Unidas. 2000. 220 p.

CEPAL. España: Inversiones y estrategias empresariales en América Latina y El Caribe", en La inversión extranjera en América Latina y El Caribe. Informe 1999. Santiago de Chile: Comisión Económica para América Latina y el Caribe-Naciones Unidas. 2000a. p. 139-177.

CEPAL México: Inversión extranjera directa y estrategias empresariales, en La inversión extranjera en América Latina y El Caribe. Informe 1999. Santiago de Chile: Comisión Económica para América Latina y el Caribe-Naciones Unidas. 2000b. p. 99-137.

CEPAL. Inversión Extranjera Directa en América Latina y el Caribe. Informe 2008. Santiago de Chile: Comisión Económica para América Latina y el Caribe-Naciones Unidas. Junio de 2009. 159 p.

CEPAL. Inversión extranjera directa en América Latina y el Caribe. Informes 2008-2013. Santiago de Chile: Comisión Económica para ]América Latina y el Cari- 
be-Naciones Unidas. 2009-2014.

CEPAL. Espacios Iberoamericanos. La inversión extranjera. Oportunidades para impulsar una relación renovada. Santiago de Chile: Comisión Económica para América Latina y el Caribe-Naciones Unidas. Noviembre de 2012.90 p.

CEPAL. La inversión Extranjera Directa en América Latina y el Caribe. Informe 2012, Santiago de Chile: Comisión Económica para América Latina y el Caribe-Naciones Unidas. Junio de 2013. 148 p.

CEPAL. La inversión Extranjera Directa en América Latina y el Caribe. Informe 2013, Santiago de Chile: Comisión Económica para América Latina y el Caribe-Naciones Unidas. Junio de 2014. 153 p.

Delgadillo de Lira, Luis de Jesús. Factores determinantes de la internacionalización de la empresa española en México. Documento de Trabajo Nebrija 2005/004. Hoyo de Manzanares, Madrid: Universidad Antonio de Nebrija. Jean Monnet European Studies Centre. 2005, pp. 51.

D.O.F. Reforma de la Ley del Servicio Público de Energía Eléctrica, Diario Oficial de la Federación, 23 de diciembre de 1992. México.

D.O.F. Ley de Inversión Extranjera. Diario Oficial de la Federación, 27 de diciembre de 1993. México.

D.O.F. Reglamento de la Ley de Inversión Extranjera y del Registro Nacional de Inversiones Extranjeras. Diario Oficial de la Federación, 8 de septiembre de 1998. México.

DOVAL ADÁN, Antonio. Las inversiones directas de España en América: 19932012. Boletín Económico de ICE, n³038, abril 2013, p. 45-56.

DURÁN HERRERA, Juan José. La empresa internacional de origen español en la crisis en GARCÍA, N. E. y RUESGA, S. M. (coords) ¿Qué ha pasado en la economía española? La gran recesión (2008 a 2013). Madrid: Pirámide. 2014. p.187-205.

DUSSEL PETERS, Enrique. La Inversión extranjera directa en México. Serie Desarrollo Productivo, ${ }^{\circ}$ 80. Santiago de Chile: CEPAL-Naciones Unidas. Octubre de 2000. 100 p.

DUSSEL PETERS, Enrique. ( coord.). Inversión extranjera directa en México: desempeño y potencial. Una perspectiva macro, meso, micro y territorial. México: Siglo xxi Editores-unam. 2007.359 p.

DUSSEL PETERS, Enrique. Inversión extranjera directa, especialización territorial e innovación en México (1994-2007), en Carrillo, Jorge (coord.). La importancia de las multinacionales en la sociedad global. Viejos y nuevos retos para México. México: El Colegio de la Frontera Norte y Juan Pablo Editor. 2012. p. 105-132.

ESQUIVEL, Eduardo. Inversión española conquista México, SDP noticias, [En línea] 18 de mayo de 2013. <http://www.sdpnoticias.com/columnas/2013/05/18/ inversion-espanola-conquista-mexico $>$ [ 15 de octubre de 2014, 21:00].

GAMESA Informe anual 2013. 2014. [En línea] <http://www.gamesacorp.com/ recursos/doc/accionistas-inversores/informacion-financiera/memoria-anual/informe-anual-2013.pdf>. [08 de junio de 2016]. 
GAS NATURAL FENOSA Informe anual integrado 2013. 2014. [En línea] <http:// wWw.gasnaturalfenosa.com/servlet/ficheros/1297144802827/IAI_2013_esp_acc. pdf $>$. [08 de junio de 2016].

GRUPO BARCELÓ Memoria anual 2013. 2014. [En línea] <http://www.barcelo.com/BarceloGroup/es_ES/Images/memoria-grupo-barcelo-2013-es30-139836. pdf>. [08 de junio de 2016].

GUTIÉRREZ, J. P. y GARCÍA DE QUEVEDO RUIZ, J. C. México: destino preferente de la Inversión Directa Española, en SOLANA GONZÁLEZ, G. (coord.). México un destino natural y estratégico. Experiencias de internacionalización de empresas españolas en mercados emergentes III. Madrid: Universidad Antonio de Nebrija. 2012. $279 \mathrm{p}$.

IBERDROLA. Informe integrado. Abril 2014. [En línea]. <https://www.iberdrola. es/webibd/gc/prod/es/doc/IA_InformeIntegradol4.pdf>. [20 de diciembre de 2014].

ICEX. Empresas españolas establecidas en México. Madrid: ICEX España Exportación e Inversiones. Ministerio de Economía y Competitividad. 23 de noviembre de $2012.53 \mathrm{p}$.

ICEX. Empresas españolas establecidas en México. Madrid: ICEX España Exportación e Inversiones. Ministerio de Economía y Competitividad. 19 de marzo de 2014. 50 p.

IE Bussiness School. 2013: Panorama de inversión española en Latinoamérica. VI Informe. Madrid: Instituto de Empresa Bussiness School. Departamento de Comunicación/Air France/KLM. Marzo de 2013. 42 p.

IE Bussiness School. 2014: Panorama de inversión española en Latinoamérica. VII Informe. Madrid: Instituto de Empresa Bussiness School. Departamento de Comunicación/Air France/KLM. Enero de 2014. 38 p.

INDITEX Memoria anual 2013. 2014. [En línea] <https://www.inditex.com/documents/10279/13717/Grupo_Inditex_Memoria_Anual_2013.pdf/c7f9b034-50464143-a442-d4fae43d759a>. [08 de junio de 2016].

INEGI. Banco de Información Económica (BIE). Producto interno bruto por entidad federativa. 2016 [en línea] <http://www.inegi.org.mx/sistemas/bie/>. [8 de junio de 2016].

INEGI. Censo de Población y Vivienda, 2010. Aguascalientes: Instituto Nacional de Estadística y Geografía. 2011. [en línea] <http://www.inegi.org.mx/est/contenidos/proyectos/ccpv/cpv2010/Default.aspx> [17 de diciembre de 2014 y 8 de junio de 2016].

INEGI. PIB por entidades federativas, 2010. Banco de Información Económica. 2012. [En línea] <http://dgcnesyp.inegi.gob.mx/>. [3 de septiembre de 2012].

LÓPEZ ESPARZA, Víctor M. El fortalecimiento de la inversión extranjera en México, Biblioteca NAFIN, n 7. México: Nacional Financiera. 1993.67 p.

MARCHINI, Geneviève. La apertura financiera y la participación extranjera en el sistema bancario mexicano, 1994-2005. México y la Cuenca del Pacífico, vol. 8, núm. 
26, septiembre-diciembre de 2005. p. 7-16.

MARTÍNEZ LÁZARO, J. C. Conclusiones del VII Informe, en IE BUSSINESS SCHOOL. 2014: Panorama de la Inversión Española en América Latina. VII Informe. Madrid: Instituto de Empresa Bussiness School, Departamento de Comunicación/ Air France/KLM. Enero de 2014. p. 28-29.

MELIÁ HOTELS INTERNATIONAL Informe financiero 2013. 2014. [En línea] <http://www.meliahotelsinternational.com/sites/default/files/informes-financieros/mhi_inf_financiero_13_es_04jun_0.pdf>.[08 de junio de 2016].

MENDOZA COTA, Jorge Eduardo. Impacto de la inversión extranjera directa en el crecimiento manufacturero en México. Revista Problemas del Desarrollo, 2011, vol. 167, n 42 , octubre-diciembre, p. 45-69.

Mercamétrica. Directorio Industridata. Empresas AAA, AA, A y B. Cuatro volúmenes. México: Mercamétrica Ediciones. 2014.

MORALES, Josefina. Inversión extranjera directa y desarrollo en América Latina. Revista Problemas del Desarrollo, 2010, vol. 163, n 41, octubre-diciembre, p. 141-156.

MORENO PINEDO, Manuel y PÉREZ CALVETE, Amparo. Relaciones económicas y comerciales entre España y México, Información Comercial Española, 821, marzo-abril 2005. p. 225-237.

MUÑOZ GUARASA, Marta. La inversión directa española en Iberoamérica ante el siglo XXI, Comercio Exterior, septiembre de 2001. p. 833-839.

OHL Cuentas Anuales e Informe de Gestión de la Sociedad (incluye Informe de Auditoría). 2014. [En línea] <http://www.ohl.es/media/52072/CCAA-OHL-Consolidado-2013-sin-firmas.pdf>. [08 de junio de 2016].

ORNELAS BERNAL, Raúl. Inversión extranjera directa y reestructuración industrial. México, 1983-1988. México: Instituto de Investigaciones Económicas, UNAM. $1991.212 \mathrm{p}$.

PAMPILLÓN, Rafael y FERNÁNDEZ, Ana Raquel. Comportamiento reciente y perspectivas de la inversión española en América Latina, Economía Exterior, 9, Madrid. 1999. p. 58-70.

PEMEX. Bloques licitados en la Cuenca de Burgos. Archivo Interno. México: Petróleos Mexicanos. 2013.

PÉREZ PINEDA, Jorge Antonio. Tendencias recientes de la inversión extranjera española en México, ECONOMÍAunam, vol. 6, número 17. 2009. p. 92-112.

PwC-COMCE. México y España en el espejo global. la. Encuesta de CEO de empresas españolas con inversión en México. Análisis de resultados. PwC México. 2011.34 pp. [en línea] <www.pwc.com/mx/encuesta-empresas-españolas> [15 de octubre de 2014].

RASO, C. México: la mina de oro de las empresas españolas con renovables, El Economista, 10 de febrero de 2014. [En línea] <http://www.eleconomista.es/energia/ noticias/5528591/02/14/Mexico-la-mina-de-oro-de-las-empresas-espanolas-con-renovables.html\#.Kku87g0GoWVV7fC> [15 de octubre de 2014]. 
RODRÍGUEZ ARANA, Alejandro. Apertura comercial, balanza comercial e inversión extranjera directa en México, 1980-2006. Investigación Económica, 2009, Vol. LXVIII, n² 269, julio-septiembre, p. 73-111.

SÁNCHEZ-SALAZAR, M. T., ALONSO, J. L. y CASADO, J. M. La inversión española en el sector eléctrico mexicano y su proyección territorial en el marco de las políticas económicas neoliberales. Estudios Geográficos, 2007. Vol. LXVIII, No. 262, enero-junio, p. 267-293 (doi:10.3989/egeogr.2007.i262.13).

SÁNCHEZ-SALAZAR, M. T. y CASADO, J. M. Mapa V.1. Infraestructura de la industria petrolera, 1980 y 2012, en SÁNCHEZ-SALAZAR, M. T. GUTIÉRREZ DE MACGREGOR, M. T. y CASADO, J. M. Atlas de cambios territoriales de la economía y la sociedad en México, 1980-201 1. México: Instituto de Geografía, UNAM. 2014.

SANTANDER. Informe Anual 2013. 2014. [En línea]. <http://www.santander. com/csgs/StaticBS?ssbinary=true \&blobkey=id\&SSURIsscontext=Satellite+Server \&blobcol=urldata \&SSURIsession=false \&blobheadervalue $\mathrm{l}=$ application $\% 2 \mathrm{Fpdf} \&-$ blobwhere $=1278704743134$ \&blobheadervalue $2=$ inline $\% 3$ Bfilename $\% 3 \mathrm{D} 152 \%$ 5C 185\% 5CInforme+Anual+2013+ACCE_new.pdf\&blobheadervalue3=santander. wc.CFWCSancomQP0 $1 \&$ SSURIapptype=BlobServer \&blobtable=MungoBlobs\&SSURIcontainer=Default\&blobheadername $1=$ content-type $\&$ blobheadername $2=$ Con tent-Disposition\&blobheadername3=appID\#satellitefragment>. [20 de diciembre de 2014].

SECRETARÍA DE ECONOMÍA. Inversión directa de España hacia México por estado y sector de destino, acumulado 1999-2013. México: Secretaría de Economía. Dirección General de Inversión Extranjera. 2014a.

SECRETARÍA DE ECONOMÍA. Flujos de IED hacia México por país de origen y sector económico de destino, 1999-2014. [En línea]. México: Secretaría de Economía. Dirección General de Inversión Extranjera. 2014b. [en línea] <http://www.economia.gob.mx/comunidad-negocios/competitividad-normatividad/inversion-extranjera-directa/estadistica-oficial-de-ied-en-mexico> [13 de octubre de 2014].

SECRETARÍA DE ESTADO DE COMERCIO. Estadísticas españolas de inversión en el exterior, 1993-2013. DataInvex. Ministerio de Economía y Competitividad. [en línea ] <http://datainvex.comercio.es/principal_invex.aspx> [23 de junio de 2014].

SEDESOL-CONAPO-INEGI. Delimitación de las zonas metropolitanas de México. México: Secretaría de Desarrollo Social-Consejo Nacional de Población-Instituto Nacional de Estadística y Geografía. 2012. [En línea] <http://www.conapo.gob.mx/ es/CONAPO/Delimitacion_zonas_metropolitanas_2010_Capitulos_I_a_IV> [17 de diciembre de 2014].

Solana González, Gonzalo (coord.). México: un destino natural y estratégico. Experiencias de internacionalización de empresas españolas en mercados emergentes III. Colección Cátedras Nebrija. Cátedra Nebrija Santander en Dirección Internacional de Empresas. Madrid: Universidad Antonio de Nebrija-Banco Santander. 2012. 277 p.

TELEFÓNICA Informe anual 2013. Informe integrado. Ser más digitales. 2014. 
[En línea] <https://www.telefonica.com/documents/153952/13347843/informe_ anual_2013_es.pdf>. [08 de junio de 2016].

TELEFÓNICA. Acerca de telefónica. Quienes somos. [En línea] <https://www. telefonica.com.mx/acerca-de-telefonica/quienes-somos>. [ 13 de junio de 2016].

UNCTAD. World Investment Report 1998. Trends and determinants. New York and Geneva: United Nations. 1998.

UNCTAD. Informe sobre inversiones en el mundo 2012. Nueva York y Ginebra: Conferencia de las Naciones Unidas sobre Comercio y Desarrollo. 2012.

UNCTAD. Informe sobre inversiones en el mundo 2013. Nueva York y Ginebra: Conferencia de las Naciones Unidas sobre Comercio y Desarrollo. 2013.

URDIALES, G.: Elecnor cumple dos décadas de éxito en México. Economía hoy. [En línea] 19 de julio de 2013.<http://www.economiahoy.mx/economia-eAm-mexico/noticias/5007232/07/13/Elecnor-cumple-dos-decadas-de-exito-en-Mexico. html\#.Kku8HIWlVXYlK4D> [ 15 de diciembre de 2014, 23:46].

ZABALLA, Juan José. México como destino de la inversión extranjera. Economía Exterior, 12. 2000. p. 52-62.

(c) Copyright: María Teresa Sánchez Salazar, José Luis Alonso Santos, José María Casado Izquierdo, 2017

(c) Copyright Scripta Nova, 2017.

Ficha bibliográfica:

SÁNCHEZ SALAZAR, María Teresa; ALONSO SANTOS, José Luis; CASADO IZQUIERDO, José María. La inversión directa de España en México en la era del neolibtalismo económico. Dinámica temporal, estructura sectorial y distribución geográfica. Scripta Nova. Revista Electrónica de Geografía y Ciencias Sociales. [En línea]. Barcelona: Universidad de Barcelona, 15 de febrero de 2017, vol. XXI, n 556. <http://revistes. ub.edu/index.php/ScriptaNova/article/view/556>.

ISSN: 1138-9788. 